\title{
Walking Control Algorithm of Biped Humanoid Robot on Uneven and Inclined Floor
}

\author{
Jung-Yup Kim, Ill-Woo Park and Jun-Ho Oh \\ HUBO Laboratory, Humanoid Robot Research Center, \\ Department of Mechanical Engineering, \\ Korea Advanced Institute of Science and Technology, \\ 373-1 Guseong-dong Yuseong-gu, Daejeon 305-701, South Korea, \\ E-mail:jungyupkim@kaist.ac.kr,jhoh@kaist.ac.kr \\ Fax : +82-42-869-8900
}

\begin{abstract}
This paper describes walking control algorithm for the stable walking of a biped humanoid robot on an uneven and inclined floor. Many walking control techniques have been developed based on the assumption that the walking surface is perfectly flat with no inclination. Accordingly, most biped humanoid robots have performed dynamic walking on well designed flat floors. In reality, however, a typical room floor that appears to be flat has local and global inclinations of about 2 degrees. It is important to note that even slight unevenness of a floor can cause serious instability in biped walking robots. In this paper, the authors propose an online control algorithm that considers local and global inclinations of the floor by which a biped humanoid robot can adapt to the floor conditions. For walking motions, a suitable walking pattern was designed first. Online controllers were then developed and activated in suitable periods during a walking cycle. The walking control algorithm was successfully tested and proved through walking experiments on an uneven and inclined floor using KHR-2 (KAIST Humanoid robot-2), a test robot platform of our biped humanoid robot, HUBO.
\end{abstract}

Key words: Walking control, biped humanoid robot, uneven floor, inclined floor, KHR-2 


\section{INTRODUCTION}

Many studies on biped walking robots have been performed since 1970 [1-4]. During that period, biped walking robots have transformed into biped humanoid robots through the technological development. Furthermore, the biped humanoid robot has become a one of representative research topics in the intelligent robot research society. Many researchers anticipate that the humanoid robot industry will be the industry leader of the 21 st century and we eventually enter an era of one robot in every home. The strong focus on biped humanoid robots stems from a long-standing desire for human-like robots. Furthermore, a human-like appearance is desirable for coexistence in a human-robot society. However, while it is not hard to develop a human-like biped robot platform, the realization of stable biped robot walking poses a considerable challenge. This is because of a lack of understanding on how humans walk stably. Furthermore, biped walking is an unstable successive motion of a single support phase.

Early biped walking of robots involved static walking with a very low walking speed [5,6]. The step time was over 10 seconds per step and the balance control strategy was performed through the use of COG (Center Of Gravity). Hereby the projected point of COG onto the ground always falls within the supporting polygon that is made by two feet. During the static walking, the robot can stop the walking motion any time without falling down. The disadvantage of static walking is that the motion is too slow and wide for shifting the COG.

Researchers thus began to focus on dynamic walking of biped robots [7-9]. It is fast walking with a speed of less than 1 second per step. If the dynamic balance can be maintained, dynamic walking is smoother and more active even when using small body motions. However, if the inertial forces generated from the acceleration of the robot body are not suitably controlled, a biped robot easily falls down. In addition, during dynamic walking, a biped robot may falls down from disturbances and cannot stop the walking motion suddenly. Hence, the notion of ZMP (Zero Moment Point) was introduced in order to control inertial forces $[10,11]$. In the stable single support phase, the ZMP is equal to the COP (Center of Pressure) on the sole. The advantage of the ZMP is that it is a point where the center of gravity is projected onto the ground in the static state and a point where the total inertial force composed of the gravitational force and inertial force of mass goes through the ground in the dynamic state. If the ZMP strictly exists within the supporting polygon made by the feet, the robot never falls down. Most research groups have used the ZMP as a walking stability criterion of dynamic biped walking. To this end, the robot is controlled such that the ZMP is maintained within the supporting polygon.

In general, the walking control strategies using the ZMP can be divided into two approaches. First, the robot can be modeled by considering many point masses, the locations of the point masses and the mass moments of inertia of the linkages. The walking pattern is then calculated by solving ZMP dynamics derived from the robot model with a desired ZMP trajectory. During walking, sensory feed back is used to 
control the robot. Second, the robot is modeled by a simple mathematical model such as an inverted pendulum system, and then the walking pattern is designed based on the limited information of a simple model and experimental hand tuning. During walking, many kinds of online controllers are activated to compensate the walking motion through the use of various sensory feedback data including the ZMP. The first approach can derive a precise walking pattern that satisfies the desired ZMP trajectory, but it is hard to generate the walking pattern in real-time due to the large calculation burden. Further, if the mathematical model is different from the real robot, the performance is diminished. On the contrary, the second approach can easily generate the walking pattern online. However, many kinds of online controllers are needed to compensate the walking pattern in real-time, because the prescribed walking pattern cannot satisfy the desired ZMP trajectory. In addition, this method depends strongly on the sensory feedback, and hence the walking ability is limited to the sensor's performance and requires considerable experimental hand tuning. The authors have developed biped humanoid robots through the second approach $[12,13]$. Specifically, various online controllers are activated and switched in the successive walking cycle.

At present, biped humanoid robot research groups have developed their own robot platforms and dynamic walking control algorithms. For example, ASIMO of HONDA, WABIAN-2 of Waseda University, and HRP-3 of AIST are well known biped humanoid robots. To date, most biped humanoid robots have performed stable dynamic walking on the well prepared flat floors. Studies involving walking on the uneven and inclined floors are still in the early stage $[14,15]$. Dynamic walking on an uneven surface is hard to realize because most biped humanoid robots perform hard position control of the joints by using motors and reduction gears and the response times of the actuators and sensors are low due to the reduction gear and sensor noise. Accordingly, it is impossible for the robot to measure the ground conditions instantaneously and it is also impossible for the robot to appropriately respond even if it measures the ground conditions rapidly. On the contrary, the human ankle can rapidly adapt to changing ground conditions. Furthermore, human muscles can contract or relax quickly with smooth motions.

This paper described a dynamic walking control algorithm that considers local and global inclinations of the floor. The authors propose the use of various online controllers to cope with an uneven and inclined floor based on an enhanced version of a previously proposed dynamic walking algorithm [13]. These online controllers are activated successively within a suitable time in a walking cycle. The performance of the algorithm is demonstrated in walking experiments using KHR-2.

This remainder of this paper is organized as follows: In Section 2, KHR-2, the test robot platform, is introduced. In Section 3, the walking pattern generation scheme for walking motion, the online controller design considering floor conditions, and activation of the online controllers during a walking cycle are described. In Section 4, the performance of the proposed walking control algorithm is assessed and demonstrated through walking experiments involving various floor conditions. Finally, Section 5 concludes the paper a discussion and plan for future work. 


\section{BIPED HUMANOID ROBOT PLATFORM, KHR-2}

KHR-2 is a biped humanoid robot developed in 2003 (Fig. 1). It has been utilized as a test robot platform to develop a walking control algorithm for the authors' biped humanoid robots, KHR-3(HUBO) and Albert HUBO [16]. The height, weight, and total number of degrees of freedom of KHR-2 are $56 \mathrm{~kg}, 120$ cm, and 41 (6 for each leg, 4 for each arm, 7 for each hand, 1 for torso, and 6 for head), respectively. All joint actuators are brushed DC motors with harmonic reduction gears or planetary gears. The authors realized a self-contained system by putting all mechanical and electronic parts into the robot body. Hence, KHR-2 is tele-operated via a wireless LAN (Local Area Network). Electrical circuit boards of joint motor controllers and sensory devices were efficiently designed for minimum energy consumption. Aluminum was used as the body frame material. The thickness and size were also minimized so as to reduce the weight within an allowable range. For human-like appearance, the ratio of each body part corresponds with the human ratio. The degrees of freedom and dimensions are summarized in Table 1.

The control system architecture of KHR-2 is a distributed control system (Fig. 2). The main computer is installed in the torso, and sub-controllers such as joint motor controllers and sensory devices are distributed throughout the body. Communication between the main computer and the sub-controllers is achieved by using a CAN (Controller Area Network) protocol. The specifications and descriptions of the sub-controllers including sensors are presented in Table 2.
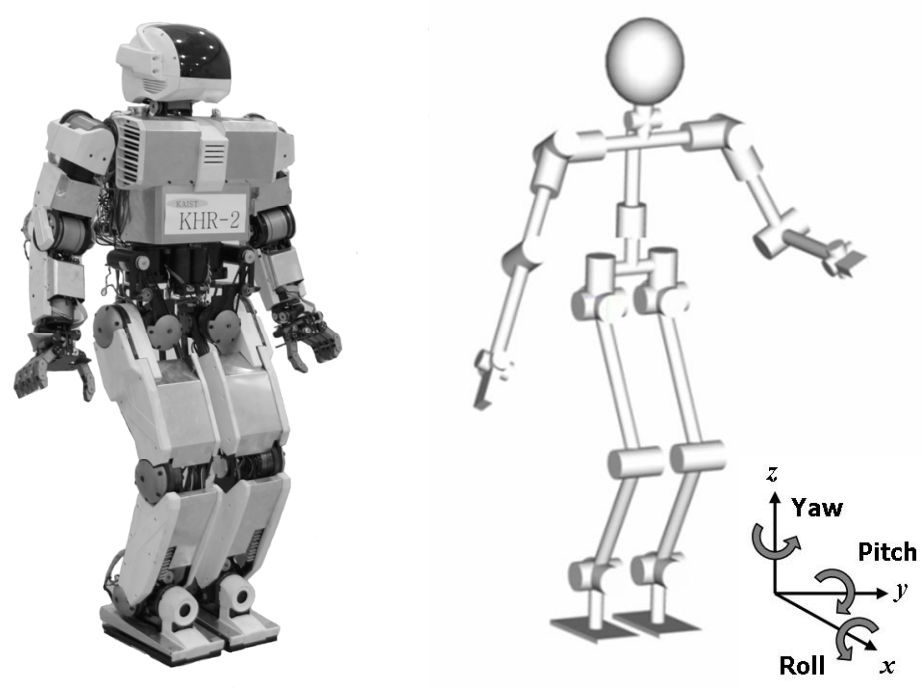

Fig. 1. Biped humanoid robot, KHR-2 


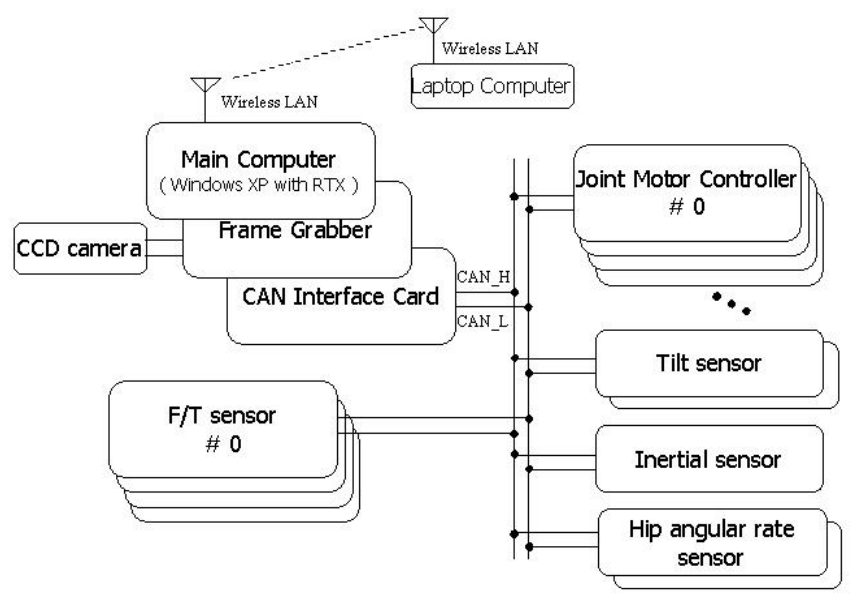

Fig. 2. Overall system configuration of KHR-2

Table 1. Degrees of freedom and dimensions of KHR-2

\begin{tabular}{|c|c|c|c|c|}
\hline \multirow{2}{*}{ Head } & Eye (pan \& tilt) & \multicolumn{3}{|c|}{$2 \mathrm{DOF} \times 2=4 \mathrm{DOF}$} \\
\hline & Neck (pan \& tilt) & \multicolumn{3}{|c|}{$2 \mathrm{DOF}$} \\
\hline \multirow{2}{*}{ Arm } & Shoulder (roll/pitch/yaw) & \multicolumn{3}{|c|}{3 DOF $\times 2=6$ DOF } \\
\hline & Elbow (pitch) & \multicolumn{3}{|c|}{$1 \mathrm{DOF} \times 2=2 \mathrm{DOF}$} \\
\hline \multirow{2}{*}{ Hand } & Wrist (roll/pitch) & \multicolumn{3}{|c|}{2 DOF $\times 2=4$ DOF } \\
\hline & Finger & \multicolumn{3}{|c|}{$1 \mathrm{DOF} \times 5 \times 2=10 \mathrm{DOF}$} \\
\hline Torso & Waist (yaw) & \multicolumn{3}{|c|}{$1 \mathrm{DOF}$} \\
\hline \multirow{3}{*}{ Leg } & Hip (roll/pitch/yaw) & \multicolumn{3}{|c|}{$3 \mathrm{DOF} \times 2=6 \mathrm{DOF}$} \\
\hline & Knee (pitch) & \multicolumn{3}{|c|}{$1 \mathrm{DOF} \times 2=2 \mathrm{DOF}$} \\
\hline & \multirow[t]{2}{*}{ Ankle (roll/pitch) } & \multicolumn{3}{|c|}{$2 \mathrm{DOF} \times 2=4 \mathrm{DOF}$} \\
\hline Total & & \multicolumn{3}{|c|}{$41 \mathrm{DOF}$} \\
\hline \multirow{5}{*}{$\begin{array}{l}\text { Dimensions } \\
\text { (mm) }\end{array}$} & Height & 1,200 & Length of upper leg & 290 \\
\hline & Width (Shoulder to shoulder) & 420 & Length of lower leg & 280 \\
\hline & Depth (Chest to back) & 213 & Length between hip joints & 142 \\
\hline & Length of upper arm & 184 & Width of sole & 140 \\
\hline & Length of lower arm & 185.5 & Length of sole & 233 \\
\hline
\end{tabular}

Table 2. Sub-controllers of KHR-2

\begin{tabular}{|c|c|}
\hline Item & Description \\
\hline \hline Joint motor controller & DC servo motor control (400W/ch or 48W/ch) \\
\hline Force/Torque sensor & $\begin{array}{c}\text { Measurement of ground reaction forces } \\
\text { ( 1 normal force up to } 1000 \mathrm{~N} \text { and 2 moments up to } 60 \mathrm{Nm})\end{array}$ \\
\hline Inertial sensor & $\begin{array}{c}\text { Measurement of roll \& pitch inclinations (up to } \pm 15 \text { degrees) of the torso using rate } \\
\text { gyros (up to } \pm 100 \text { degrees/sec) and accelerometers (up to } \pm 2 \mathrm{~g} \text { ) }\end{array}$ \\
\hline Tilt sensor & $\begin{array}{c}\text { Measurement of ground roll \& pitch inclination (up to } \pm 15 \text { degrees) and } \\
\text { Forward \& lateral acceleration (up to } \pm 2 \mathrm{~g} \text { ) of foot }\end{array}$ \\
\hline Hip angular rate sensor & $\begin{array}{c}\text { Measurement of roll angular velocities (up to } \pm 100 \text { degrees/sec) } \\
\text { of right \& left hip }\end{array}$ \\
\hline
\end{tabular}




\section{BIPED WALKING AND ONLINE CONTROL ALGORITHM CONSIDERING FLOOR CONDITION}

In this section, a suitable walking pattern design for dynamic biped walking and an online control technique considering the floor conditions are described. To make the robot walk, a gait trajectory is designed offline. In the biped robotics research field, the gait trajectory, otherwise known as the walking pattern, generates the relative position trajectories of two feet with respect to the pelvis center. Even a well-designed walking pattern cannot prevent the robot from falling down as a result of large upper body motions, vibrations of the body parts, and an uneven floor. Therefore, an online walking control algorithm composed of various online controllers is essential to maintain the dynamic balance in real-time. These online controllers can finely compensate the joints trajectories (Fig. 3).

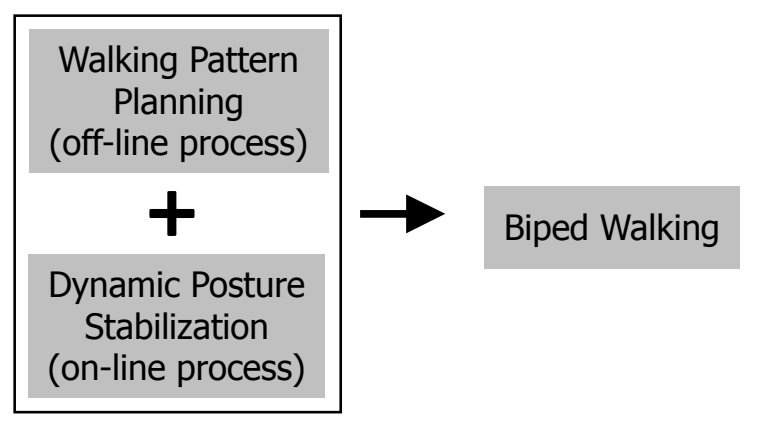

Fig. 3. Realization of biped walking

\subsection{Walking Pattern Generation}

For the design of the walking pattern, the authors considered the following four design factors.

1) Walking cycle $(2 \times$ step time $)$

2) Lateral swing amplitude of the pelvis

3) Double support ratio

4) Forward landing position ratio of the pelvis

The walking cycle was set by using the natural frequency of a 2D simple inverted pendulum model as shown in Fig. 4 in order to produce natural swings. The natural frequency of the $2 \mathrm{D}$ simple inverted pendulum $f_{n}$ is derived as equation (1). Here, $l$ is the length of the pendulum and $g$ is the gravitational acceleration. In the case of KHR-2, $l$ is $0.9 \mathrm{~m}$ : hence, the natural frequency, the walking cycle, and the step time are $0.525 \mathrm{~Hz}, 1.9$ seconds, and 0.95 second according to equation (1). 


$$
f_{n}=\frac{1}{2 \pi} \sqrt{\frac{g}{l}}
$$

The lateral swing amplitude of the pelvis also can be derived by means of the ZMP dynamics of a 2D simple inverted pendulum model. The equation of motion of a simple inverted pendulum model can be written as follows;

$$
T=m g l \theta-m l^{2} \ddot{\theta}
$$

Where, $T$ is the torque at the joint, $m$ is the point mass and $\theta$ is the angular displacement. Then, if we divide the right and left parts by $m g$, we have

$$
\frac{T}{m g}=l \theta-\frac{l}{g}(l \ddot{\theta})
$$

By substituting $F_{z}=m g$ and $l \theta=Y_{m c}$ into equation (3) under an assumption that $\theta$ is small $(\theta<5$ degrees), then we obtain

$$
\frac{T}{F_{z}}=Y_{m c}-\frac{l}{g}\left(\ddot{Y}_{m c}\right)
$$

Where, $F_{z}$ is the ground reaction force, $Y_{m c}$ is the lateral displacement of mass center. ZMP is practically calculated through dividing the torque $T$ at the joint by the ground reaction force $F_{z}$. Thus, we can finally get following ZMP dynamics.

$$
Y_{z m p}=Y_{m c}-\frac{l}{g} \ddot{Y}_{m c}
$$

Where, $Y_{z m p}$ is the lateral ZMP. When the robot is walking, we can assume the lateral displacement of the mass center as $Y_{m c}=A \sin \omega t$ on the coronal plane. Then, we obtain

$$
Y_{z m p}=A\left(1+\frac{l}{g} \omega^{2}\right) \sin \omega t
$$

Here, when the walking frequency $\omega\left(=2 \pi f_{n}\right)$ and the lateral swing amplitude of the pelvis $A$ are chosen as $3.3 \mathrm{rad} / \mathrm{sec}$ and $32 \mathrm{~mm}$, the amplitude of $Y_{z m p}$ becomes $64 \mathrm{~mm}$. Moreover, in real robot's walking, $A$ becomes larger than the original value due to deflection of the compliant force/torque sensor 
structures attached at the ankle joints. If it is assumed that the robot tilts at about 0.5 degree more, the real $A$ is about $39 \mathrm{~mm}$, and hence $Y_{z m p}$ becomes $78 \mathrm{~mm}$. The $Y_{z m p}$ of $78 \mathrm{~mm}$ is a suitable value for locating the ZMP on the near the foot center. In addition, its value has a roughly 10 percent of margin considering the lateral distance between the pelvis center and the ankle joint is $71 \mathrm{~mm}$.

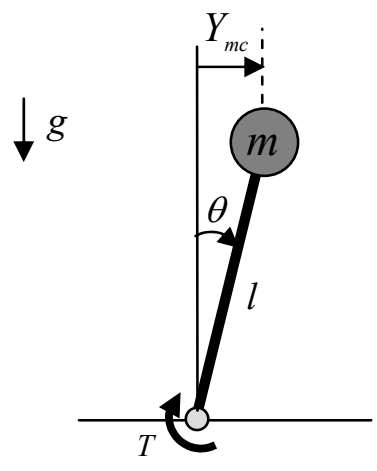

Fig. 4. A simple inverted pendulum model

The double support ratio is the time percentage that both feet are in contact with the floor during a single walking cycle (Fig. 5). In the case of humans, the human's double support ratio is about over 10 percent [17], whereas KHR-2's double support ratio is 5 percent because it does not have toe joints.

The forward landing position ratio of the pelvis $\gamma_{\text {pelvis }}$ represents the pelvis forward position with respect to the hind leg at the moment the double support phase starts (Fig. 6). That is, if the forward landing position ratio of the pelvis is near 1.0, the pelvis is nearer to the fore leg at the start of the double support phase. As shown in Fig. 7, it can be observed that the robot acts like a simple inverted pendulum which is swinging in forward direction. If we assume the forward displacement of the mass center as $X_{m c}=A \sin \omega t$ on the sagittal plane, the ZMP dynamics in forward direction also can be written as follows:

$$
X_{z m p}=X_{m c}-\frac{l}{g} \ddot{X}_{m c}
$$

where, $X_{m c}$ is the forward displacement of mass center, $l$ is the length of the pendulum, $X_{z m p}$ is the forward ZMP, and $g$ is the gravitational acceleration, respectively. In the double support phase, considering the phases of $X_{m c}$ and $\ddot{X}_{m c}$ are equal, $\ddot{X}_{m c}$ is nearly zero because $X_{m c}$ is located at near zero that represents the center position of swing trajectory. Hence, we can assume the $X_{z m p}$ is almost equal to $X_{m c}$ from the equation (7) in the double support phase. In this point of view, if we place the pelvis at certain point with respect to the center position between the two feet, its projected position onto the ground is the $X_{z m p}$. In this paper, $\gamma_{\text {pelvis }}$ was experimentally set to 0.45 by considering suitable walking motions and stable walking, thus the $X_{z m p}$ is slightly nearer to the rear foot. 
By considering these four factors, the walking pattern was designed as shown in Fig. 9. The design parameters are represented in Table. 3. To eliminate discontinuity of the velocity profile, a cosine function was used to generate smooth curves. Fig. 8 shows a ground fixed coordinate frame for design of the joint trajectories of the walking pattern. Consequently, each joint trajectory is derived by solving the inverse kinematics and is then transferred to the joint motor controllers.

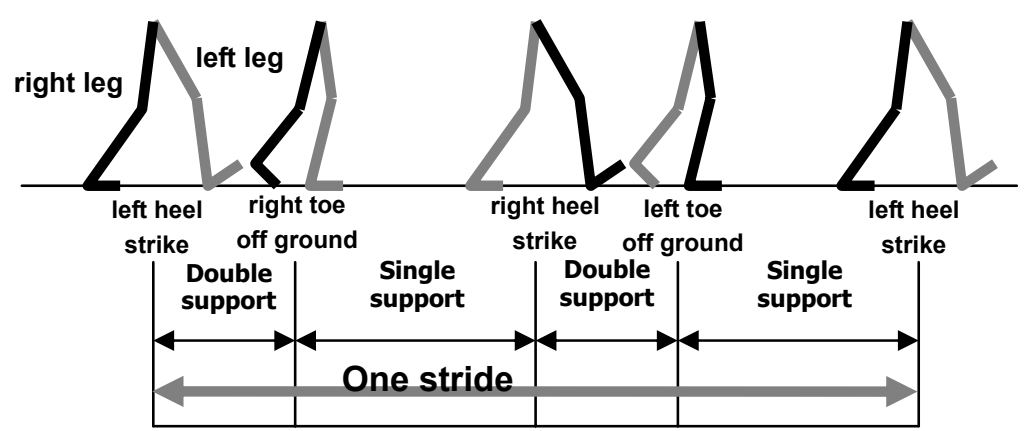

Fig. 5. Walking cycle

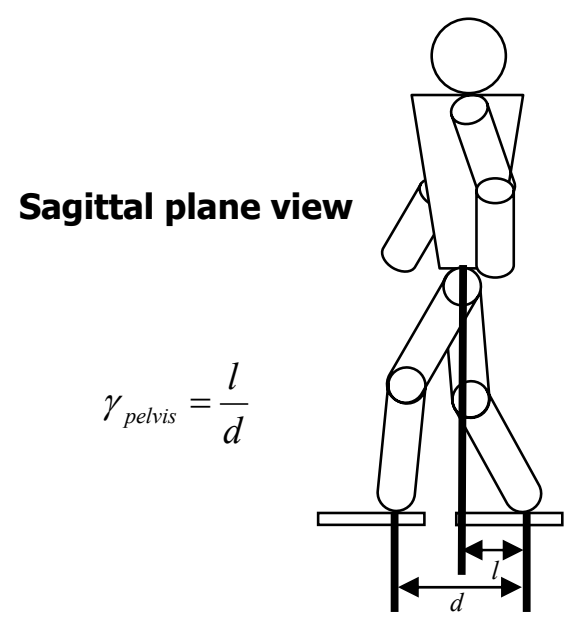

Fig. 6. Forward landing position ratio of the pelvis

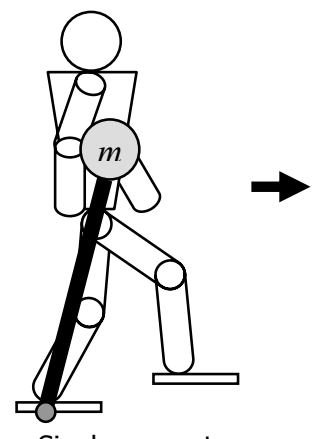

Single support

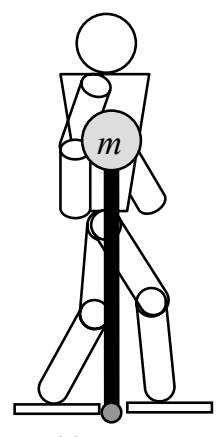

Double support

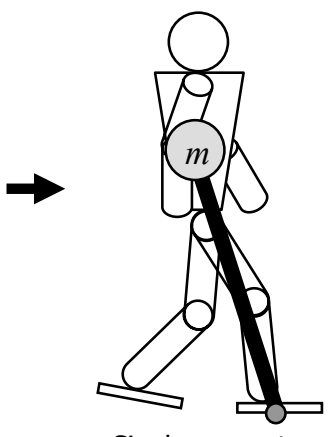

Single support

Sagittal plane view

Fig. 7. Forward landing position ratio of the pelvis 


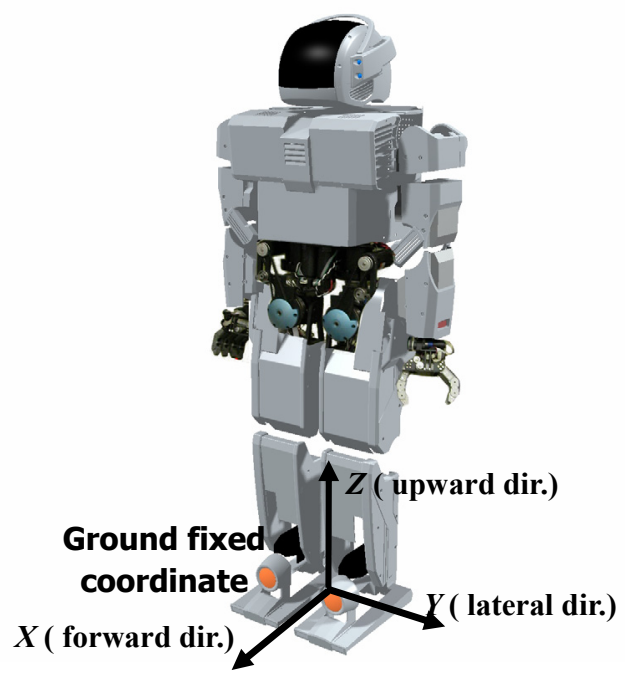

Fig. 8. Coordinate frame

Table 3. Design parameters of walking pattern

\begin{tabular}{|c|c|c|}
\hline & Description & Value \\
\hline $\boldsymbol{A}_{\text {pelvis }}$ & Lateral swing amplitude of pelvis & $32(\mathrm{~mm})$ \\
\hline $\boldsymbol{H}_{\text {foot }}$ & Maximum elevation of foot & $40(\mathrm{~mm})$ \\
\hline $\boldsymbol{d}$ & Step length (stride/2) & $200(\mathrm{~mm})$ \\
\hline $\boldsymbol{T}_{\text {stride }}$ & Walking period (stride time) & $1.9(\mathrm{~seconds})$ \\
\hline $\boldsymbol{T}_{\text {step }}$ & Step time & $0.95(\mathrm{~seconds})$ \\
\hline $\boldsymbol{T}_{\text {delay }}$ & Delay time & $0.2(\mathrm{~second})$ \\
\hline $\boldsymbol{\kappa}_{d s p}$ & Double support ratio & $0.05(5 \%)$ \\
\hline $\boldsymbol{T}_{\text {ssp }}$ & Single support time & $T_{\text {step }} \times\left(1.0-\kappa_{d s p}\right)$ \\
\hline $\boldsymbol{T}_{\text {dsp }}$ & Double support time & $T_{\text {step }} \times \boldsymbol{\kappa}_{d s p}$ \\
\hline$\gamma_{\text {pelvis }}$ & Forward landing position ratio of & \\
\hline & the pelvis & 0.45 \\
\hline
\end{tabular}



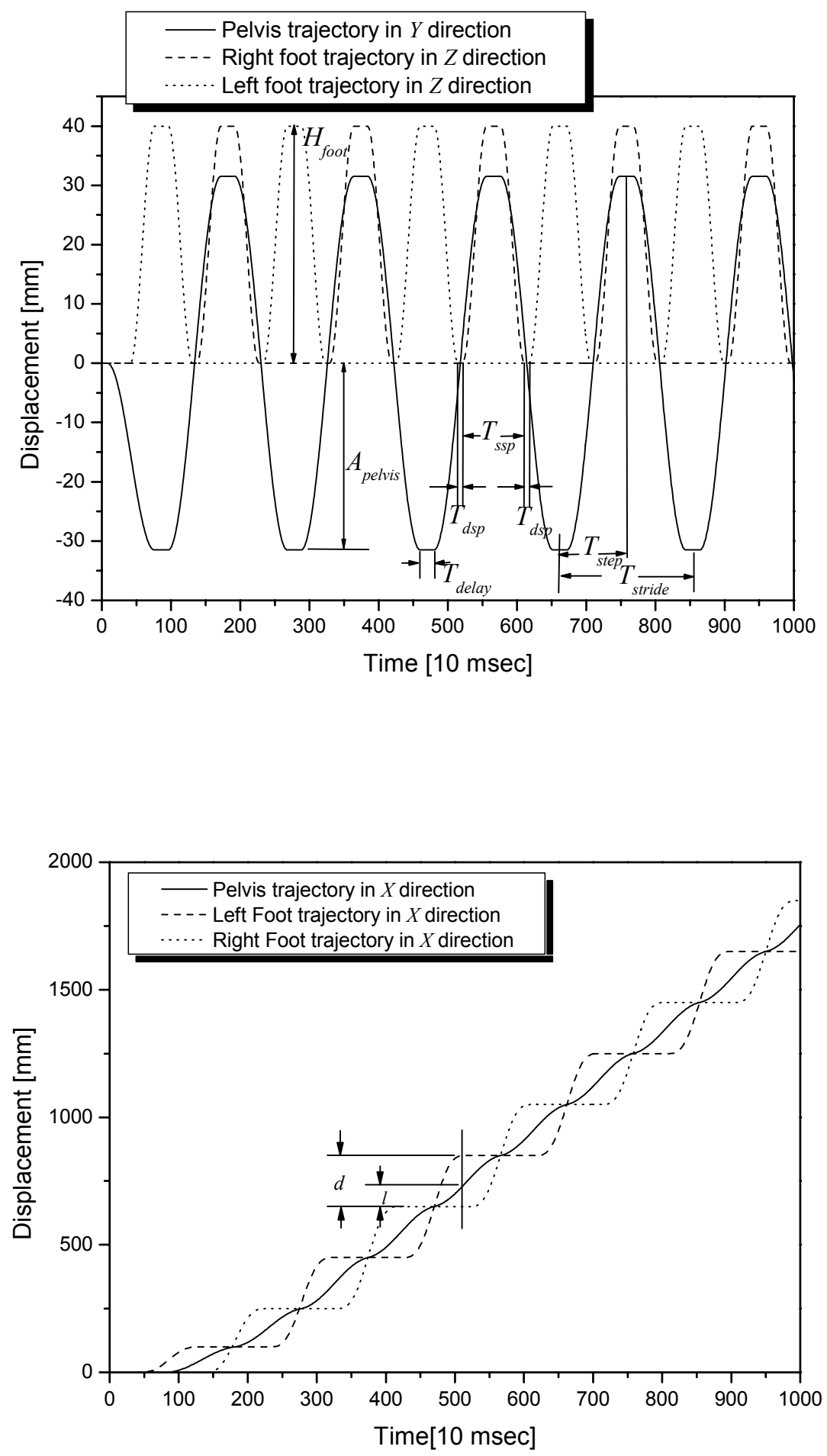

Fig. 9. Walking pattern design 


\subsection{Walking Control Algorithm}

In this section, the authors proposed an online controller design and suitable use of online controllers in a walking cycle. The proposed walking control method is based on a controller switching strategy, and thus it is important to divide the walking cycle into several walking stages. In each walking stage, suitable online controllers are activated. Fig. 10 shows the walking stages and their descriptions are as follows:

1) $1^{\text {st }}$ stage : lift the left leg to its maximum flexion and height

2) $2^{\text {nd }}$ stage : lower the left leg until it makes complete contact with the ground

3) $3^{\text {rd }}$ stage : lift the right leg to its maximum flexion and height

4) $4^{\text {th }}$ stage : lower the right leg until it makes complete contact with the ground

5) $5^{\text {th }}$ stage : this stage follows the 1 st or 3 rd stage, and brings the robot to a standing pose with both legs landed on the ground

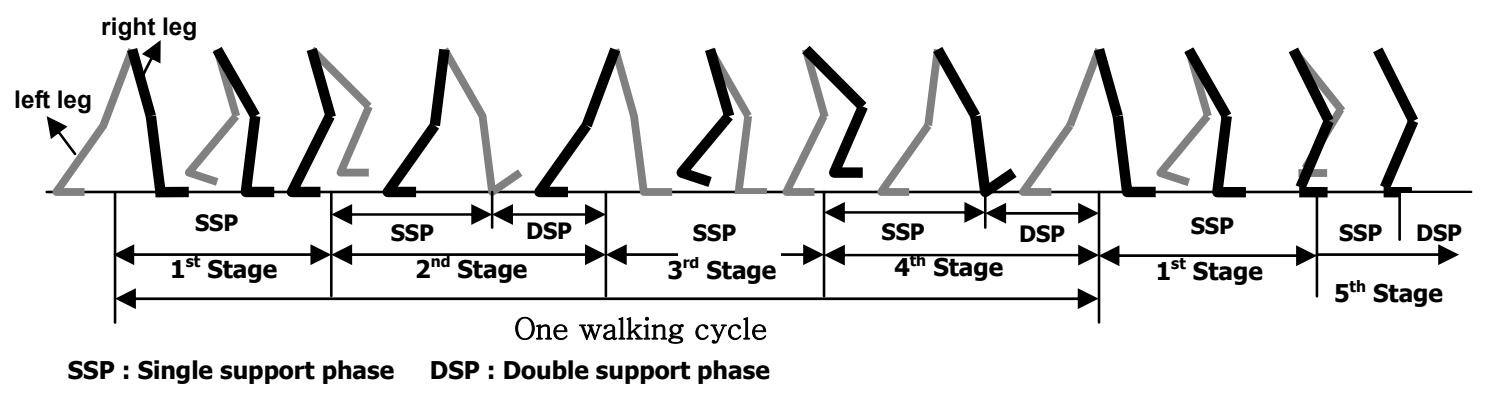

Fig. 10. Walking stage

During walking, the walking stages $1 \sim 4$ are repeated continuously. In particular, in the $2^{\text {nd }}$ and $4^{\text {th }}$ walking stages, the single and double support phases coexist. The authors have developed a walking control algorithm that is composed of three control strategies [13], a real-time balance control strategy, a walking pattern control strategy, and a predicted motion control strategy. Each control strategy is composed of several online controllers according to the objective of the strategy. In Table 4, a previous walking control algorithm that does not consider uneven and inclined floor conditions is summarized. The previous walking control algorithm could make the robot walk stably on a normal room floor. However, the biped humanoid robots have to walk stably on uneven and inclined asphalt roads or footpaths in order to operate in the human society. Hence, online controllers that can cope with various ground conditions are integrated into the system. The proposed online controllers have been added to our previous walking control algorithm. 
Table 4. Brief summary of the previous walking algorithm [13]

\begin{tabular}{|c|c|c|}
\hline $\begin{array}{l}\text { Control } \\
\text { Scheme }\end{array}$ & $\begin{array}{l}\text { Online Controller } \\
\text { (working period) }\end{array}$ & Objective \\
\hline \multirow{3}{*}{$\begin{array}{l}\text { Real-Time } \\
\text { Balance Control }\end{array}$} & $\begin{array}{c}\text { Damping controller } \\
\left(1^{\text {st }} \text { and } 3^{\text {rd }} \text { Stages, }\right. \\
\left.\text { SSPs of } 2^{\text {nd }} \text { and } 4^{\text {th }} \text { Stages }\right)\end{array}$ & $\begin{array}{c}\text { Eliminate the upper body oscillations in single support } \\
\text { phase by imposing damping at the ankle joints }\end{array}$ \\
\hline & $\begin{array}{c}\text { ZMP compensator } \\
\left(1^{\text {st }} \text { and } 3^{\text {rd }} \text { Stages, }\right. \\
\left.\text { SSPs of } 2^{\text {nd }} \text { and } 4^{\text {th }} \text { Stages }\right)\end{array}$ & $\begin{array}{l}\text { Maintain dynamic balance by horizontal motions of the } \\
\text { pelvis }\end{array}$ \\
\hline & $\begin{array}{l}\text { Soft landing controllers } \\
\left.\text { (DSPs of } 2^{\text {nd }} \text { and } 4^{\text {th }} \text { Stages }\right)\end{array}$ & $\begin{array}{l}\text { Absorb landing impact and adapt the foot to the ground } \\
\text { surface }\end{array}$ \\
\hline \multirow{2}{*}{$\begin{array}{l}\text { Walking Pattern } \\
\text { Control }\end{array}$} & $\begin{array}{l}\text { Pelvis swing amplitude controller } \\
\left.\text { (DSPs of } 2^{\text {nd }} \text { and } 4^{\text {th }} \text { Stages }\right)\end{array}$ & $\begin{array}{l}\text { Compensate the lateral swing amplitude of the pelvis by } \\
\text { considering the amplitude of the ZMP }\end{array}$ \\
\hline & $\begin{array}{l}\text { Torso pitch/roll controller } \\
\left.\text { (DSPs of } 2^{\text {nd }} \text { and } 4^{\text {th }} \text { Stages }\right)\end{array}$ & $\begin{array}{l}\text { Compensate the center position of the pelvis swing to } \\
\text { balance the pitch \& roll inclinations of the torso }\end{array}$ \\
\hline \multirow{2}{*}{$\begin{array}{c}\text { Predicted } \\
\text { Motion Control }\end{array}$} & $\begin{array}{l}\text { Tilt over controller } \\
\left(1^{\text {st }} \text { and } 3^{\text {rd }} \text { Stages }\right)\end{array}$ & $\begin{array}{l}\text { Compensate the ankle joint trajectories to prevent "tilt } \\
\text { over" in roll direction }\end{array}$ \\
\hline & $\begin{array}{l}\text { Landing position controller } \\
\qquad\left(2^{\text {nd }} \text { and } 4^{\text {th }} \text { Stages }\right)\end{array}$ & $\begin{array}{c}\text { Compensate the landing position to prevent unstable } \\
\text { landing }\end{array}$ \\
\hline
\end{tabular}

\subsubsection{Upright Pose Controller}

This new online controller was designed to allow the robot to walk stably on a globally inclined floor. If the floor is globally inclined, the robot is tilted in the direction of floor inclination, so the robot walking becomes unstable. To prevent the tilting of the robot during walking, the authors proposed the upright pose controller, which makes the robot upright all the time. In general, the global inclination of the floor continuously changes slowly as the robot proceeds across the floor surface, and hence it is relatively easy to handle. Here, a measurement of the global inclination of the floor is a key factor. The authors have measured this through the use of an inertial sensor at the torso. A 2-axis accelerometer is installed in the inertial sensor, and it can be employed as an inclinometer by using a very heavy low pass filter. That is, signals due to the fast movement of the robot can be filtered, and the floor inclination is then measured from the robot torso's inclination, which is caused by the slowly changing floor inclination. By measuring the time varying global inclination, the upright pose controller keeps the robot's torso upright all the time. Fig. 11 shows the schematics of the upright pose control. As for the pitch control, the upright pose controller superimposes the control input of the PI controller using the torso pitch error $\theta_{\text {err }, p}^{\text {torso }}$ on the prescribed ankle trajectory $u_{\text {ankle pitch }}$ as follows:

$$
u_{\text {ankle pitch }}^{\prime}=u_{\text {ankle pitch }}+\left(K_{p}+\frac{K_{I}}{s}\right) \theta_{\text {err }, p}^{\text {toro }}
$$


Where, $K_{p}$ and $K_{I}$ are the proportional and integral gains, $u_{\text {ankle pitch }}^{\prime}$ is the compensated ankle pitch angle. As for the roll control, in the same manner, the upright pose controller also superimposes the control input of the PI controller using the torso roll error $\theta_{e r r, r}^{\text {torso }}$ on the prescribed distance between the hip joint and the ankle joint, $l_{R}$ or $l_{L}$. The upright pose controller is activated in all walking stages. Following equations represents the control law.

$$
\begin{gathered}
l_{L}^{\prime}=l_{L}+\left(K_{p}+\frac{K_{I}}{s}\right) \theta_{\text {err }, r}^{\text {torso }} \\
l_{R}^{\prime}=l_{R}-\left(K_{p}+\frac{K_{I}}{s}\right) \theta_{\text {err }, r}^{\text {torso }} \\
u_{\text {ankle roll }}^{\prime}=u_{\text {ankle roll }}+\tan ^{-1}\left(\frac{l_{R}^{\prime}-l_{L}^{\prime}}{\text { Lateral distance between ankle joints }}\right)
\end{gathered}
$$

Where, $K_{p}$ and $K_{I}$ are the proportional and integral gains, $u_{\text {ankle roll }}^{\prime}$ is the compensated ankle roll angle. $u_{\text {ankle roll }}^{\prime}$ can be calculated geometrically from $l_{R}$ and $l_{L}$. In this manner, the robot always keeps its torso upright against the global inclination of the floor. Therefore, the robot can walk stably in spite of the global inclination of the floor.

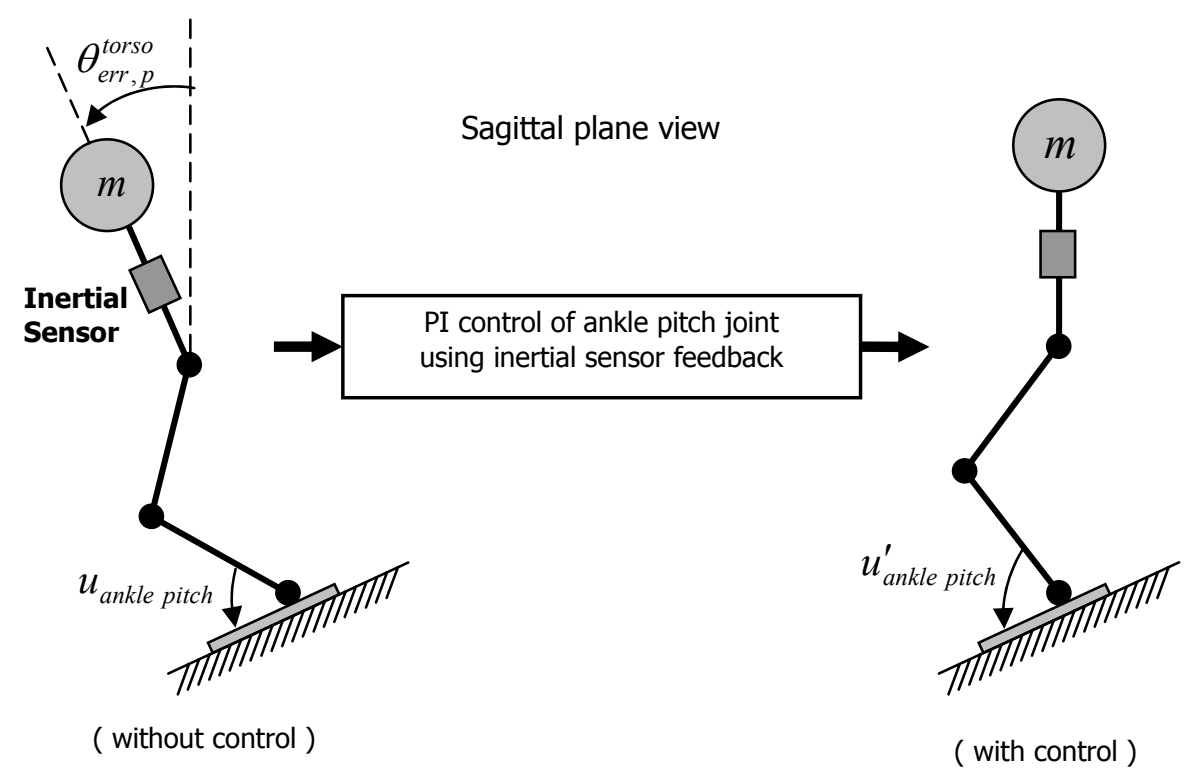

(a) Pitch control 


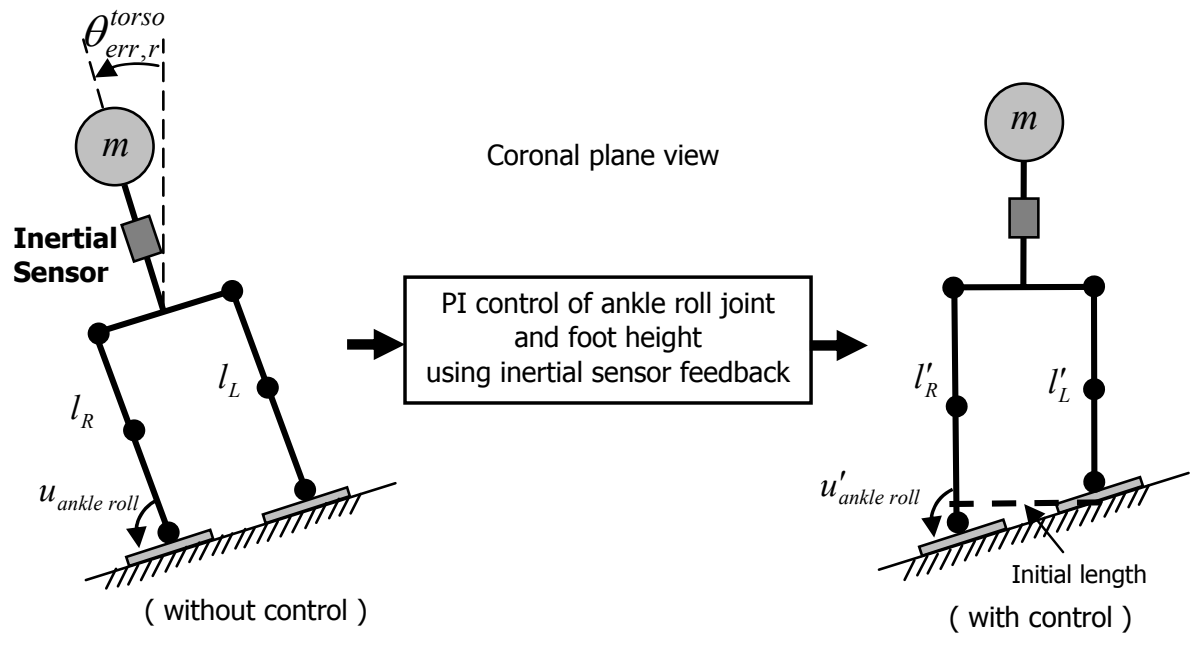

(b) Roll control

Fig. 11. Schematics of upright pose control

\subsubsection{Landing Angular Momentum Control}

It is difficult for the robot to walk on an uneven floor even if the floor is not globally inclined. A typical room floor has a local inclination of about $1 \sim 2$ degrees. It is important to note that the small amount of the inclination can cause a serious instability. Moreover, the local inclination does not have any tendency and is changeable at every step. Due to the local inclination of the floor, the robot may fall down easily. Hence, it is necessary to overcome the local inclination of the floor. The most fundamental preparation for the local inclination is that the sole has to be supported by 4 points as a flat sole cannot be fixed at the moment of landing. To be robust against the local inclination of the floor, the authors proposed the control strategy which uses the angular momentum. The control principle of the landing angular momentum control is described as follows under the assumption that the landed sole is perfectly fixed on the floor.

1) When $5 \mathrm{kgf}$ of ground reaction force is measured on the landing foot, the angular velocity of the hip is read and the angular momentum is then calculated.

2) If the calculated angular momentum does not exist within the allowable range, the moment $M$ from the equation (9) is applied to the ankle joint of the landed foot immediately for the time $\Delta t$.

$$
\text { Impulsive plane motion : } I \omega_{\text {desired }}=I \omega_{\text {measured }}+M \Delta t
$$

3) If the angular momentum comes into the allowable range before $\Delta t$ passes, the landing angular 
momentum control is deactivated.

In equation (9) above, I $\omega_{\text {measured }}$ is the real angular momentum after landing, $I \omega_{\text {desired }}$ is the desired angular momentum after landing, $M$ is the moment applied to the ankle joint of the landed foot, and $\Delta t$ is the applied time. In this paper, $I \omega_{\text {desired }}$ is $11 \mathrm{~kg} \cdot \mathrm{m}^{2} \mathrm{rad} / \mathrm{s}$ and $\Delta t$ is 0.1 second. The moment $M$ is PI controlled by using the feedback torque signal of a force/torque sensor, as shown in Fig. 12. Here, $T_{\text {desired }}$ is the desired torque, $T_{\text {measured }}$ is the real torque from the force/torque sensor, $u_{\text {ankle }}$ is the compensatory input angle, $k_{i}$ and $k_{p}$ are integral and proportional gains. Consequently, $u_{\text {ankle }}$ is superimposed on the prescribed ankle trajectory.

In this manner, the robot's ankle can be adapted to the locally inclined floor immediately and produce a suitable angular momentum at every step.

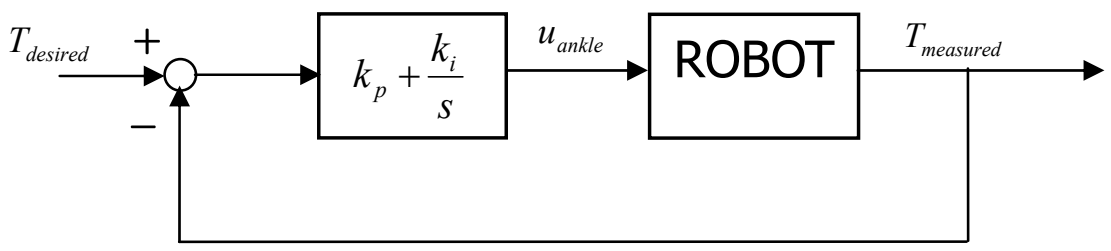

Fig. 12. Ankle torque control block diagram

\subsubsection{Landing Shock Absorber}

When a robot walks on an uneven floor, the altitude of the floor is always changing. For example, even if the robot lowers the landing foot to the prescribed altitude, the foot may not contact the floor. On the contrary, the landing foot may contact the floor before the foot is lowered to the prescribed position. In general, the second case occurs frequently because the supporting frame between the pelvis and the hip joint can be deflected due to the joint compliance and flexibility of the aluminum frame when the leg is swinging. Therefore, the foot of swinging leg can not be raised to desired height. If the foot lands early, the leg strongly pushes down on the floor with large impact. This large impact makes the robot to shake, thus the walking becomes unstable. Therefore, for the stable walking, the vertical displacement of the foot should be controlled in order to reduce the landing impact. The authors controlled the pelvis height through the use of a force/torque sensor as though a spring-damper system was installed between the pelvis and the ankle joint. The principle is written as follows and is illustrated in Fig. 13.

1) Evaluate the floor contact by measuring $5 \mathrm{kgf}$ of the ground reaction force.

2) If early landing occurs, stop foot lowering and then compensate the pelvis height by a virtual springdamper system. 
A virtual spring-damper system is installed between the hip joint and ankle joint so that the vertical shock at the moment of landing can be absorbed through rapid modification of the height of the hip joint. Equation (10) represents the control input of the landing shock absorber, which is superimposed on the prescribed height of the hip joint.

$$
z_{c}=z+\frac{F_{z}(s)}{m s^{2}+c s+k}
$$

Here, $F_{z}$ is the measured normal force, $c$ is the damping coefficient, $k$ is the stiffness, $z$ is the reference pelvis height, $z_{c}$ is the compensated reference pelvis height, and $m$ is the equivalent mass. $c$ and $k$ were suitably tuned by walking experiments so that the virtual shock absorber can reduce the impact sufficiently.

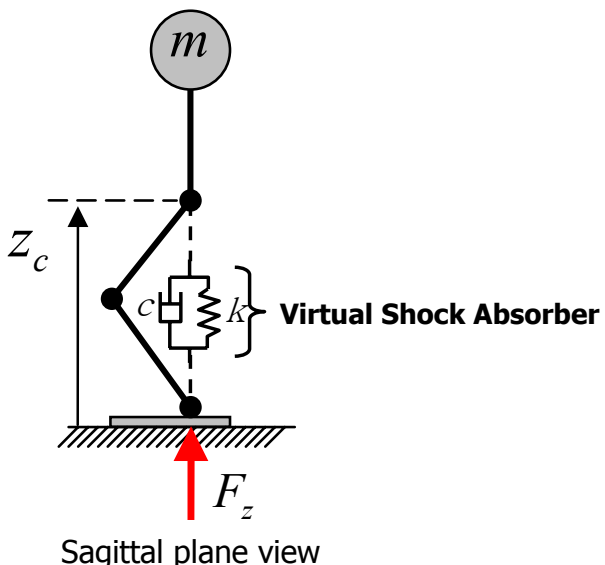

Fig. 13. Schematic of the landing shock absorber.

\subsubsection{Landing Timing Controller}

During walking, landing timing of each foot is prescribed by walking pattern design. It is important to note that prescribed landing timing does not provide excellent landing at every step because landing timing of prescribed walking pattern is just for ideal case that the floor is perfectly flat with no inclination and the robot is not tilted. Hence, it is necessary to compensate the landing timing for the best landing. Our conventional landing timing controller only suspended the walking pattern flow if the foot does not contact the floor at the end of foot lowering. This late landing is caused by tilting outside of the robot due to local inclination of the supporting foot. On the contrary, if the robot is tilted inside, it has to land the lifted foot before the prescribed time to prevent the falling down (Fig. 14). The authors call this case an 
early landing. In the case of outside tilt over, if the robot does not fall down, the problem can be easily solved by suspending the walking pattern flow until the ground reaction force is detected on the sole of the lowering foot. However, inside tilt over should be detected by sensor feedback in advance. The authors attached rate gyros at the right and left hips in roll direction and then compensated the landing timing by using angular velocity data. The roll angular velocity of the hip was derived from the left hip rate gyro during the left leg supporting and from the right hip rate gyro during right leg supporting. Fig. 15 shows the usual experimental data of the roll angular velocity of the hip during forward walking. The reason why the authors drew the angular velocity and the foot trajectories in Z-direction together is that the zero crossing of the angular velocity usually occurs during the maximum height of each foot. Fig. 16 shows the schematics of landing timing control. The $x$-axis of the figure is time and the $y$-axis is the angular velocity for the rate gyros or displacement for the foot height. For convenience, the angular velocity was drawn as a straight line. In a normal case, the roll angular velocity usually passes through the $x$-axis between A and B because the direction of the lateral displacement of the pelvis changes at the maximum altitude of the swinging foot with a little time delay. If inside tilt over occurs, the angular velocity of the hip passes through the $x$-axis before A. Hence, in this case, it is necessary to lower the lifted foot earlier. More specifically, the principle is written as follows:

1) In the $1^{\text {st }}$ or $3^{\text {rd }}$ walking stage, derive the zero crossing point where the roll angular velocity of the hip passes through the $x$-axis.

2) In the case where the zero crossing point is between $A$ and B, the early landing does not occur. Hence, after more than $5 \mathrm{kgf}$ of the ground reaction force that informs the ground contact is measured on the foot at the end of the $2^{\text {nd }}$ or $4^{\text {th }}$ walking stage, the $1^{\text {st }}$ or $3^{\text {rd }}$ walking stage starts for continuous walking.

3) In the case where the zero crossing point is time E before A, lower the lifted foot on the floor time $E$ before the prescribed time.

In this manner, the robot can land the foot on the ground at the best timing at every step, thus it can walk more stably.

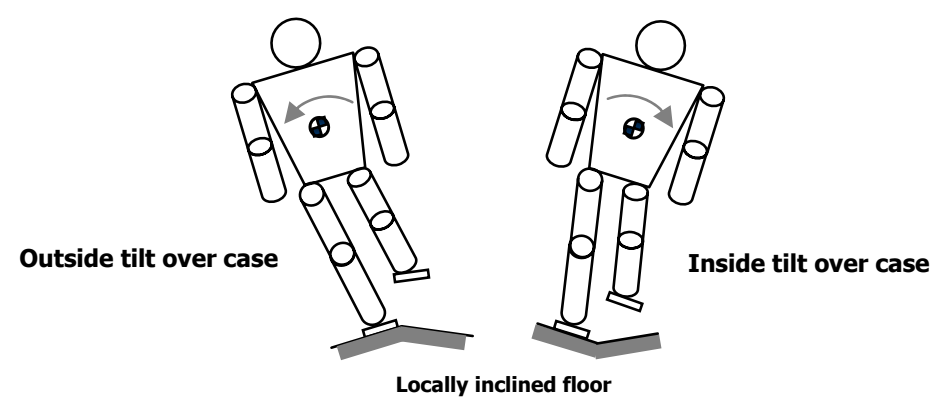

Fig. 14. Schematics of tilt over cases. 


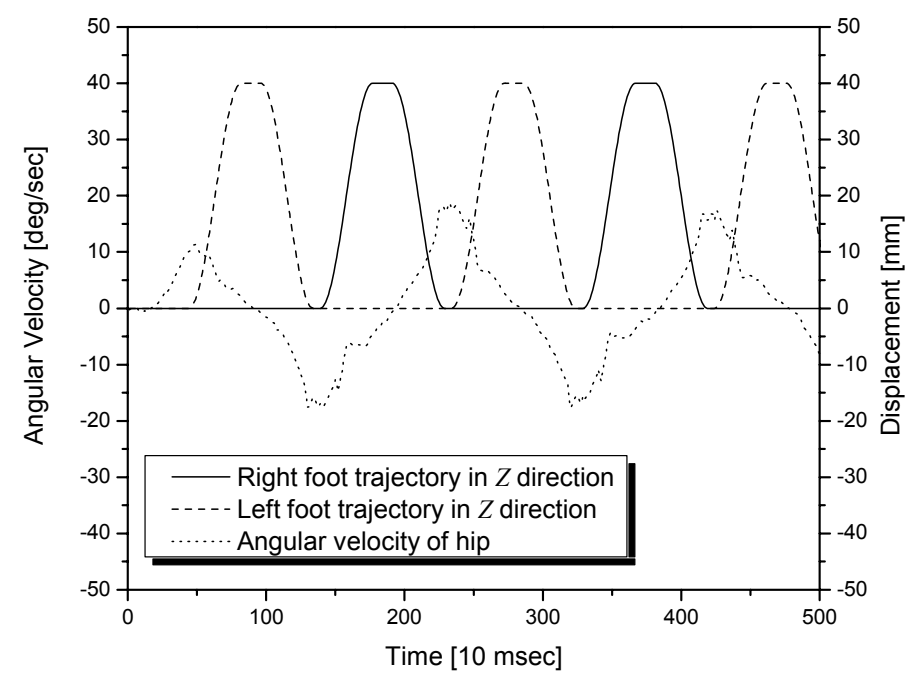

Fig. 15. Experimental result of angular velocity of hip and foot trajectories in $Z$ direction

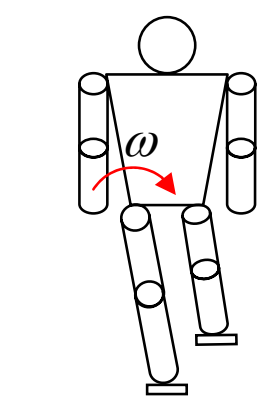

(Coronal Plane View)

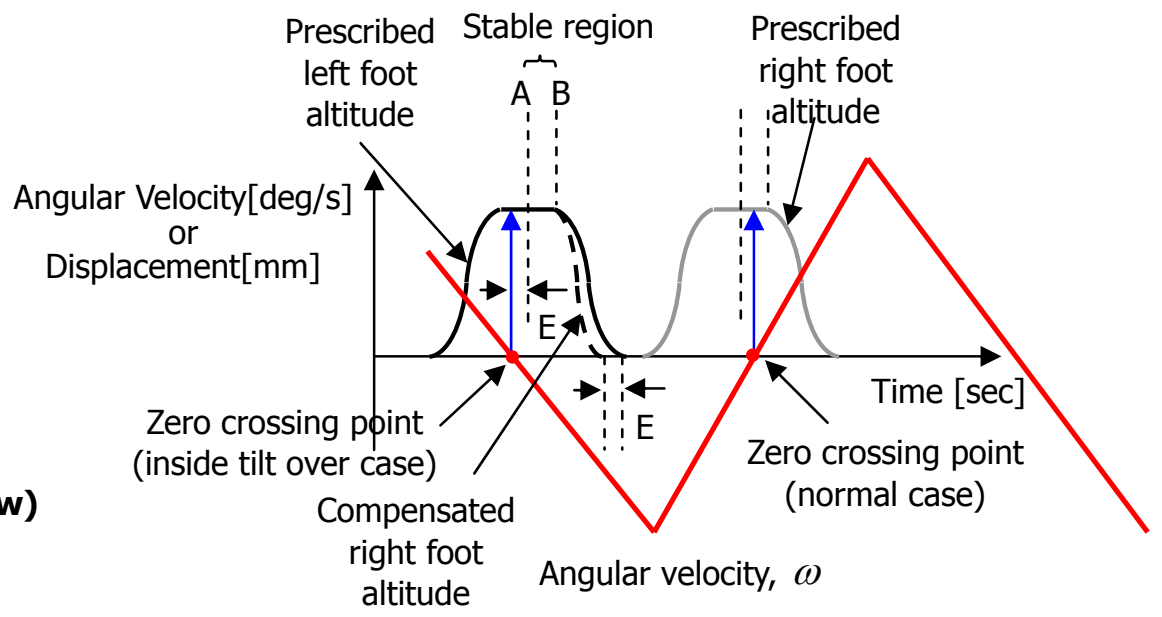

Fig. 16. Schematics of landing timing control

\subsubsection{Landing Position Controller}

Similar to the landing timing, it is important to compensate the landing position. The landing timing and position are the most important factors in biped walking control as the walking is ultimately realized by these two factors. If we consider a human walking on a single position, the landing position on the floor is continuously changing. This phenomenon represents humans determine the landing position which produces suitable angular momentum through the use of vestibular organ. For example, if the angular velocity of the human is so much large during landing, the human will land the foot far away from the 
body center in order to reduce the angular velocity after landing. Likewise, a biped walking robot also has to compensate the landing position from the prescribed landing position through the sensor feedback. The authors compensate the landing position before landing by using the angular momentum so that the robot can land the foot at the suitable position which is predicted to generate moderate angular momentum at every step. The rate gyro is attached on the hip because the angular velocity signal of the hip is clearer than that of the torso. Since the frames between the pelvis and leg are flexible and the reduction gears of the hip joints are compliant, there is a great deal of noise in the angular velocity of the torso. Hence, the authors attached the rate gyros on the hip, which is near the torso. Fig. 17 shows the robot just before landing and just after landing. Equation (11) mathematically represents the landing motion as an impulsive motion on a coronal plane.

$$
I \omega_{A L}=I \omega_{B L}+M \Delta t
$$

Here, $\omega_{B L}$ is the angular velocity just before landing, $\omega_{A L}$ is the angular velocity just after landing, and $I$ is the mass moment of inertia with respect to the supporting point. $M$ is a moment applied to the ankle joint at the start of landing, and $\Delta t$ is the applied time of $M . I \omega_{A L}$ is the desired angular momentum just after landing, and $I \omega_{B L}$ is the measured angular momentum just before landing. Therefore, it is important to regulate $I \omega_{A L}$ constantly by using $M \Delta t$ as a control input, because $I \omega_{B L}$ is variable at every step. Equation (11) can be written as follows:

$$
I\left(\omega_{A L}-\omega_{B L}\right)=\left(M_{\text {ankle }}+m g d\right) \Delta t
$$

Here, $M_{\text {ankle }}$ is the applied moment at the ankle joint due to the ground reaction force at the start of landing, and $m g d$ is the applied moment at the ankle joint due to the gravitational force. Consequently, the landing position $d$ which is the distance from the body center is calculated by the following equation.

$$
d=\frac{\left(\frac{I\left(\omega_{A L}-\omega_{B L}\right)}{\Delta t}-M_{\text {ankle }}\right)}{m g}
$$

Moreover, in reality, $d$ is prescribed by walking pattern. If we call a prescribed landing position $d_{\text {pre }}$, the landing position compensation can be derived by multiplying the difference between $d$ and $d_{\text {pre }}$ by a proportional gain $k_{p}$. Equation (14)) Finally, the final landing position $d_{\text {final }}$ can be obtained by adding the compensation to the prescribed landing position $d_{p r e}$.

$$
d_{\text {final }}=d_{\text {pre }}+k_{p}\left(d-d_{\text {pre }}\right)
$$



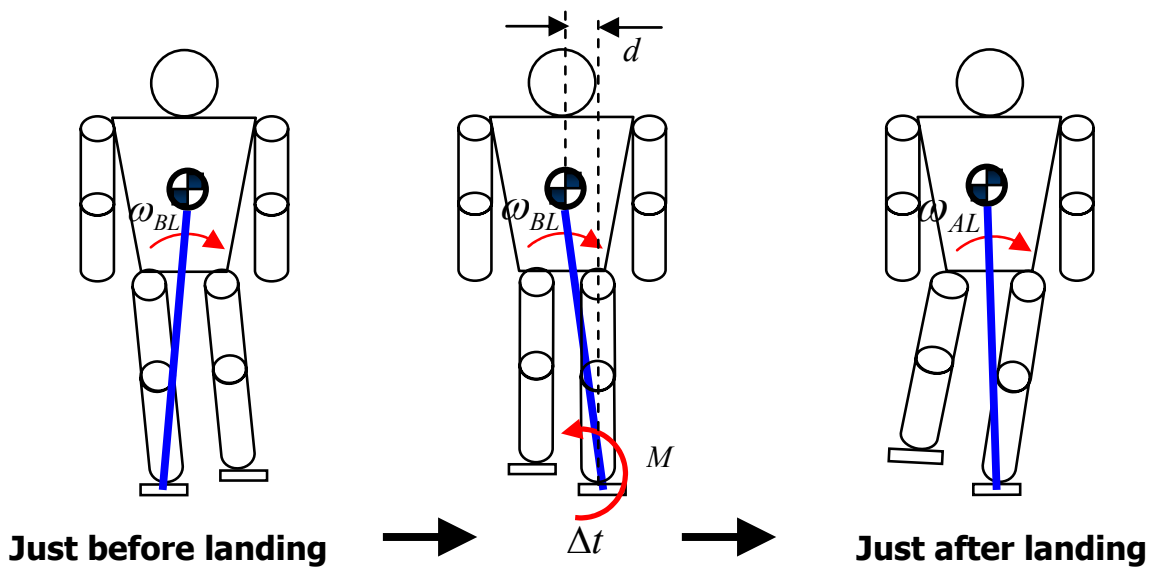

Fig. 17. The schematics of landing position control

\subsubsection{Vibration Reduction Controller}

When a biped humanoid robot is walking, the swinging leg vibrates. This is because the connecting frame between the leg and pelvis is deflecting and the reduction gear is slightly compliant. While the vibrations are not large, they disturb the precise landing position control of the foot. If the position control accuracy is not within $\pm 3 \mathrm{~mm}$, the performance of the landing position controller is diminished. Therefore, the vibration reduction is fundamentally necessary for the landing position controller, so the authors proposed the vibration reduction controller in order to reduce the vibrations of foot. Fig. 18 represents a mathematical model of a swinging leg.
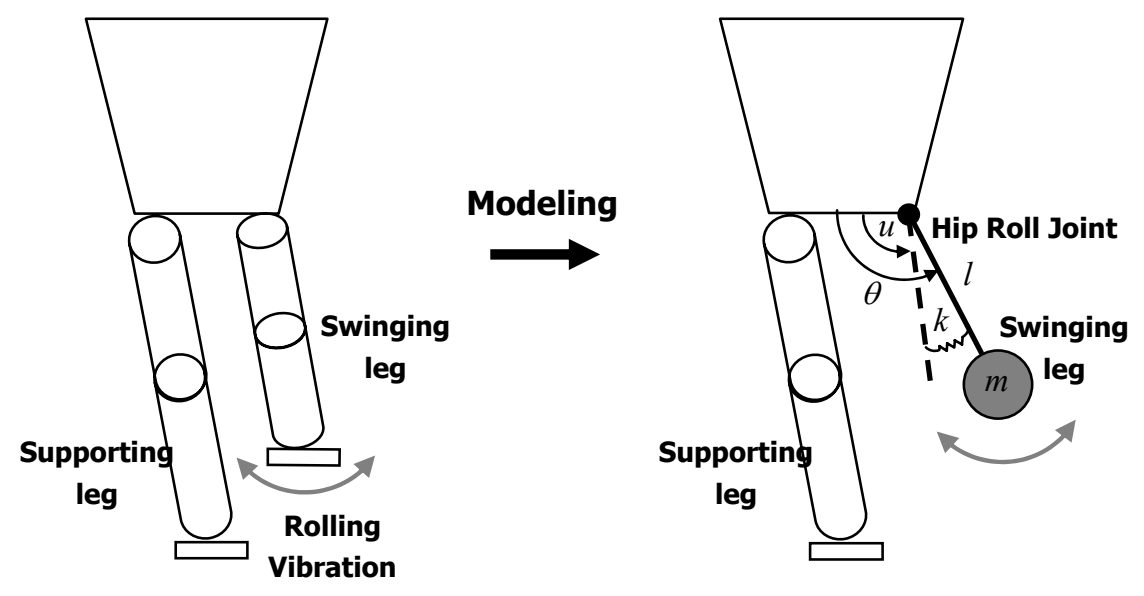

Coronal Plane View

Fig. 18. A simple mathematical model of the leg

In Fig. 18, $u$ is the control input angle of hip joint, $\theta$ is the actual angle of hip joint, $m$ is the point 
mass of a leg, $l$ is the distance from the hip joint to the mass center, and $k$ is the torsional stiffness of the spring. The equation of motion of the system is derived as follows:

$$
m l^{2} \ddot{\theta}=-k(\theta-u)
$$

Thus, the transfer function is

$$
G(s)=\frac{\theta(s)}{u(s)}=\frac{k / m l^{2}}{s^{2}+k / m l^{2}}
$$

The transfer function shown above is a marginally stable system that has two poles on an imaginary axis in the Laplace domain. To derive $k / m l^{2}$, the period of vibration was calculated by free vibration experiments of the lifted foot in the static single support phase. The exact transfer function of the rolling joint of the hip joints as determined experimentally is

$$
G(s)=\frac{746.2}{s^{2}+746.2}
$$

The control block diagram was designed as shown in Fig. 19 in order to place the closed loop poles to the LHP (Left Half Plane) with a suitable damping ratio. In the figure, $\ddot{\theta}$ was measured by an accelerometer attached on the sole. The angular position was calculated by using $1 /(s+2)^{2}$ instead of $1 / s^{2}$ in order to prevent large over shoot due to the slant of the lifted foot. The authors experimentally determined $\alpha$ as 200 and $\beta$ as 100. A suitable control gain $K$ was also experimentally derived through hand tuning. A control input $u$ was finally superimposed onto the prescribed hip rolling joint trajectories. Fig. 18 presents the experimental result when the impulse was applied to the foot in the static single support phase with or without the control. The lateral acceleration of the foot was observed to effectively damp down with the control. Consequently, the effectiveness of the control strategy was experimentally demonstrated.

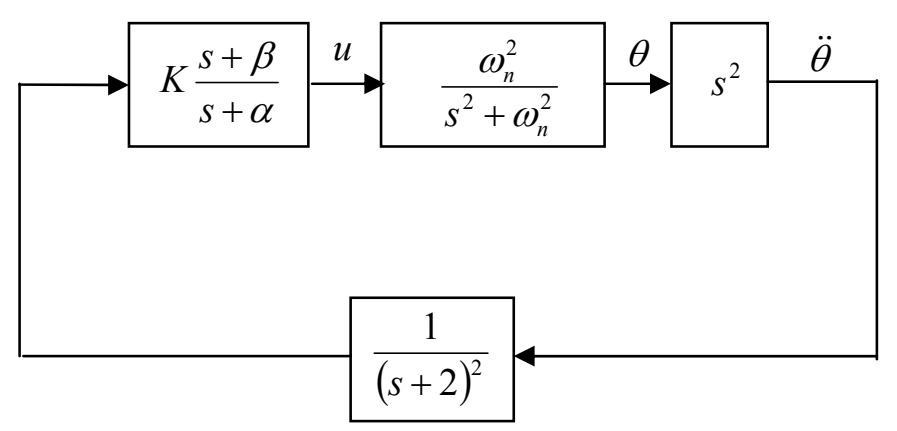

Fig. 19. Vibration reduction control block diagram 


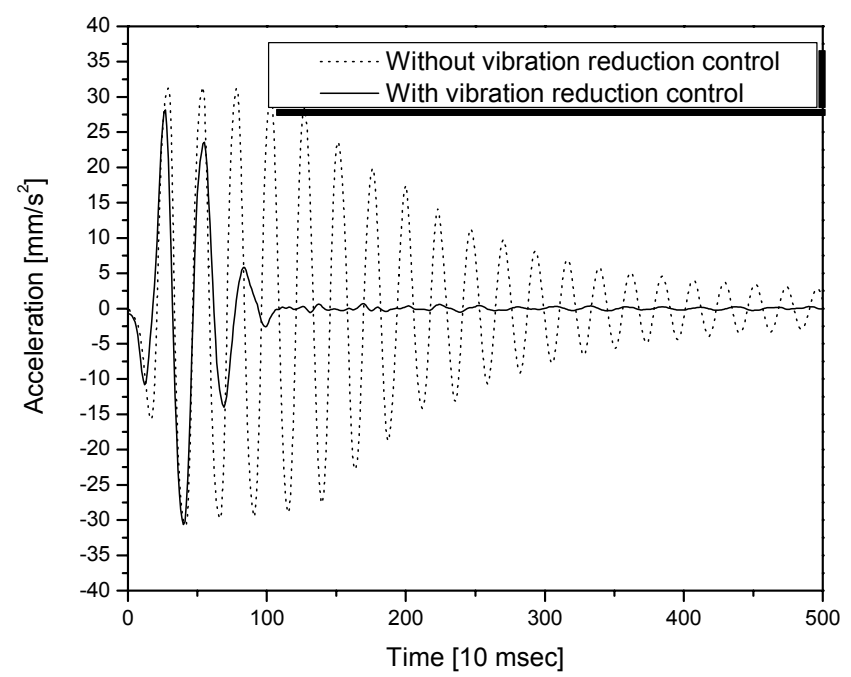

Fig. 20. Free vibration responses of the lifted foot with or without control in the static single support phase.

\subsection{Activation Schedule of Online Controllers}

We now describe a suitable activation schedule of the proposed online controllers outlined in the above section. The activation schedule of the online controllers is shown in Fig. 21 for a single walking cycle (1 4 walking stage). The control input of each online controller is superimposed onto the prescribed angle trajectory or the Cartesian position trajectory of the joint. In this manner, the walking pattern is modified in real-time so that the walking robot can walk stably on an uneven and inclined floor. These online controllers were added to the previous walking control algorithm described in Table 4. In addition, the online controllers are summarized in Table 5.

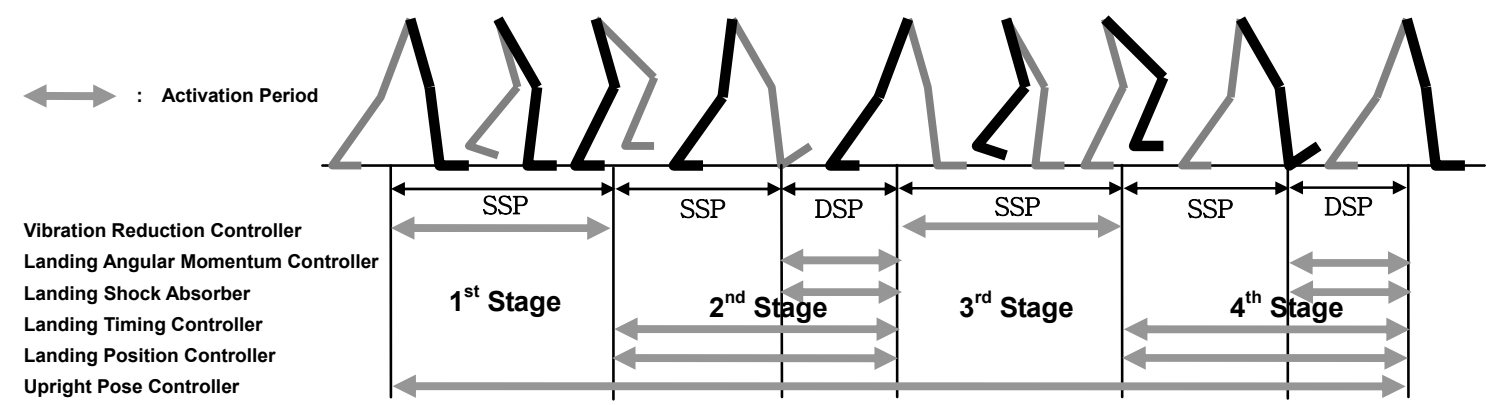

Fig. 21. Schematic of the activation schedule of online controllers 
Table 5. Summary of the proposed online controllers

\begin{tabular}{|c|c|c|}
\hline $\begin{array}{l}\text { Control } \\
\text { Scheme }\end{array}$ & $\begin{array}{l}\text { Online Controller } \\
\text { (working period) }\end{array}$ & Objective \\
\hline \multirow{5}{*}{$\begin{array}{c}\text { Real-Time } \\
\text { Balance } \\
\text { Control }\end{array}$} & $\begin{array}{l}\text { Vibration reduction controller } \\
\qquad\left(1^{\text {st }} \text { and } 3^{\text {rd }} \text { Stages }\right)\end{array}$ & $\begin{array}{l}\text { Reduces the foot vibrations during leg swinging to enhance } \\
\text { performance of the landing position control }\end{array}$ \\
\hline & $\begin{array}{l}\text { Landing angular momentum controller } \\
\qquad \text { (DSPs of } 2^{\text {nd }} \text { and } 4^{\text {th }} \text { Stages) }\end{array}$ & $\begin{array}{l}\text { Regulates the angular momentum after landing against the } \\
\text { local inclination of floor }\end{array}$ \\
\hline & $\begin{array}{l}\text { Landing shock absorber } \\
\left.\text { (DSPs of } 2^{\text {nd }} \text { and } 4^{\text {th }} \text { Stages }\right)\end{array}$ & $\begin{array}{l}\text { Absorbs the landing impact during walking to prevent the } \\
\text { shaking of robot }\end{array}$ \\
\hline & $\begin{array}{l}\text { Landing timing controller } \\
\qquad\left(2^{\text {nd }} \text { and } 4^{\text {th }} \text { Stages }\right)\end{array}$ & $\begin{array}{l}\text { Adjusts the landing time in the case of the tilt-over due to } \\
\text { the local inclination of the floor }\end{array}$ \\
\hline & $\begin{array}{l}\text { Upright pose controller } \\
\text { (All the time) }\end{array}$ & $\begin{array}{l}\text { Keeps the robot upright all the time against global } \\
\text { inclination of floor }\end{array}$ \\
\hline $\begin{array}{c}\text { Predicted } \\
\text { Motion } \\
\text { Control }\end{array}$ & $\begin{array}{l}\text { Landing position controller } \\
\qquad\left(2^{\text {nd }} \text { and } 4^{\text {th }} \text { Stages }\right)\end{array}$ & $\begin{array}{l}\text { Compensates the landing position before landing for the } \\
\text { moderate landing against the global and local inclinations }\end{array}$ \\
\hline
\end{tabular}

\section{BIPED WALKING EXPERIMENTS ON UNEVEN AND INCLINED FLOOR}

In this section, biped walking experiments on an uneven and inclined floor are described. For the test robot platform, the authors' biped humanoid robot KHR-2 was used. The various floor conditions are presented in Fig. 22. The local inclination was established by randomly and densely attaching the rubber plates having dimensions of $30 \mathrm{~mm}$ (width) $\times 30 \mathrm{~mm}$ (height) $\times 4 \mathrm{~mm}$ (thickness) on a $16 \mathrm{~mm}$ thick and flat aluminum plate. The global inclination was achieved by tilting the aluminum plate. For repeatability, consistency, and accuracy, the performance of the algorithm was evaluated on the various floor conditions through the walking on the spot first. Furthermore, the algorithm was also verified through a forward walking experiment on the uneven room floor.

Fig. 23 shows the torso inclinations for walking on each floor case without considering floor conditions. The local inclination was \pm 2 degrees in any direction and the global inclination was +2 degrees in the roll and pitch direction. As shown in the figures, in the $1^{\text {st }}$ floor case, the torso inclination was measured within about \pm 0.8 degree. This value represents the walking was very stable and smooth. However, in other cases, the ranges of torso inclination were much larger. For $2^{\text {nd }}$ and $3^{\text {rd }}$ floor case, the torso inclinations were fluctuated with an about 2 degrees of amplitude, so the robot looked a little unstable. In particular, the walking was seriously unstable for the $4^{\text {th }}$ floor case. Eventually, the robot fell down in this case during walking. In the figures, the pitch angle of the torso is smaller than the roll angle of the torso. This is because the sole length is much longer than the width, thus the robot is basically more stable in 
pitch direction.

Fig. 24 represents the torso inclinations during walking on each floor case with consideration of the floor conditions. The local inclination was \pm 2 degrees and the global inclination was +3 degrees in the roll and pitch direction. The authors raised the angle of the global inclination from +2 degrees to +3 degrees. For the ideal $1^{\text {st }}$ case, the torso inclination was also measured within about \pm 0.8 degree. This range is quite similar to the experimental result of the $1^{\text {st }}$ case in Fig. 23. This means the control strategy for uneven and inclined floor is not activated on the flat and non-inclined floor. In the $2^{\text {nd }}$ and $3^{\text {rd }}$ cases, the ranges were only \pm 1 degree. This value represents the walking was stable enough so far. Furthermore, in the $4^{\text {th }}$ case, the inclination was measured within \pm 2 degrees even though the global inclination was +3 degrees. This range is not quite stable but the walking looked stable. When we compare Fig. 24 (d) with Fig. 23 (d), it is observed that the drastic change was achieved even though the floor condition of Fig. 24(d) was worse than that of Fig. 23(d). Therefore, the authors experimentally proved the effectiveness of the proposed control strategy for uneven and inclined floor.

Fig. 25 show the control inputs of the walking experiment of Fig. 24(d). In Fig. 25 (a), the compensatory ankle joint angles and the distances between the hips and ankle joints were generated by the upright pose controller against the global inclination of the uneven floor. In Fig. 25 (b), against the local inclination, the compensatory ankle roll joint angles were generated in a moment in order to add the angular impulse into the supporting leg's ankle. After supporting, the compensatory angles became zero during rising of the foot. Fig. 25 (c) shows the altitude of the two feet. By using the angular velocity data, the landing timing was compensated in every step, and hence the double support time was also variable. In Fig. 25 (d), it is observed that the landing position was compensated to generate suitable angular velocity after the landing. Figs. 25 (e) and (f) show the compensation of the pelvis height for reducing the landing impact and the ground reaction forces of both feet.

Next, the authors evaluated the proposed algorithm's performance through forward walking of KHR-2. The forward walking experiments were performed on a normal room floor. The normal room floor has $\pm 1 \sim 2$ degrees of local inclination and $\pm 0 \sim 1$ degrees of global inclination. In order to provide more unevenness, rubber plates whose dimensions are $120 \mathrm{~mm}$ (width) $\times 120 \mathrm{~mm}$ (height) $\times 4 \mathrm{~mm}$ (thickness) were attached on the room floor. Fig. 26 shows the torso inclination of the robot and the ground reaction forces during forward walking. The step length was $200 \mathrm{~mm}$ and the torso inclination was measured within \pm 2 degrees. In the case of the forward walking, the range of pitch angle of the torso was larger than that of the walking on the spot because the forward inertial force occurred. Eventually, it can be known that the roll and pitch angles of the torso were measured within a stable range, thus KHR-2 could walk stably on the uneven room floor. A snapshot of the experiment is shown in Fig. 27. 
$1^{\text {st }}$ case

(perfectly flat

\& noninclined)

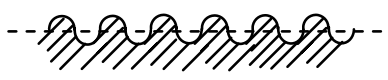

$2^{\text {nd }}$ case

(locally inclined)

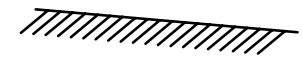

$3^{\text {rd }}$ case

(globally inclined)

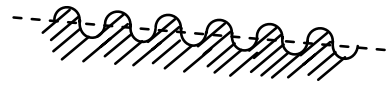

$4^{\text {th }}$ case

(locally \& globally inclined)

Fig. 22. Various floor cases

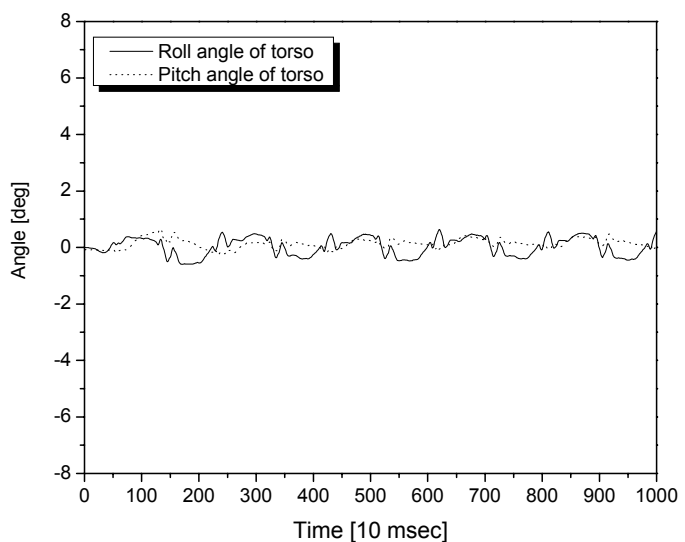

(a) 1 st floor case

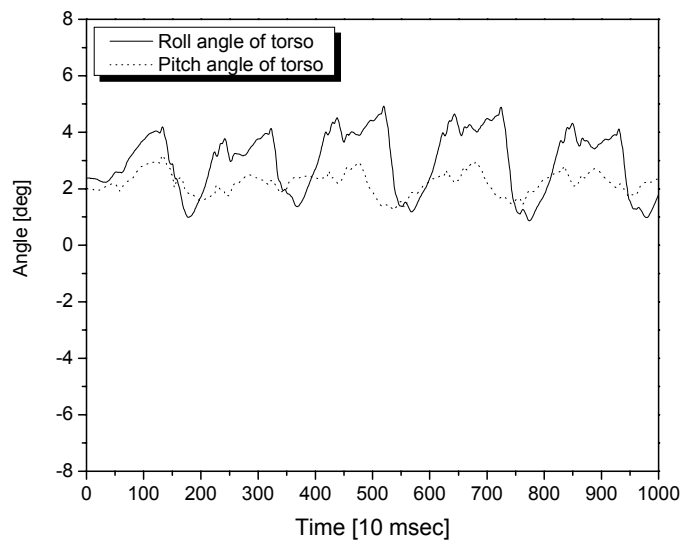

(c) 3rd floor case (global slope : +2 deg in pitch \& roll)

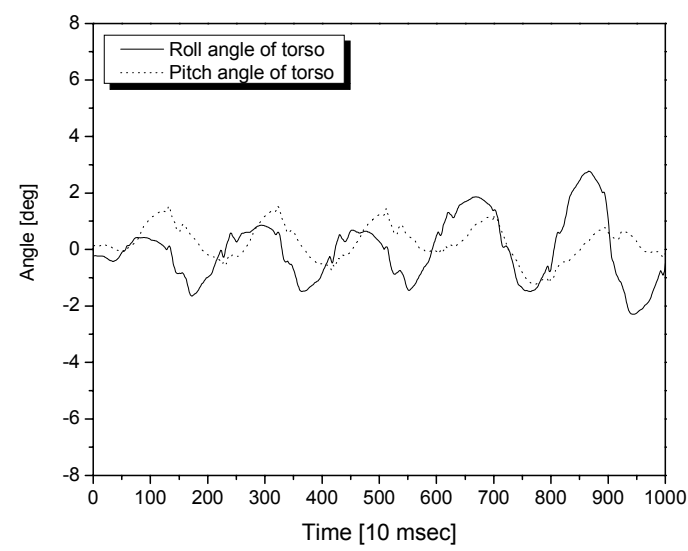

(b) 2nd floor case (local slope : +-2.0 deg in pitch \& roll)

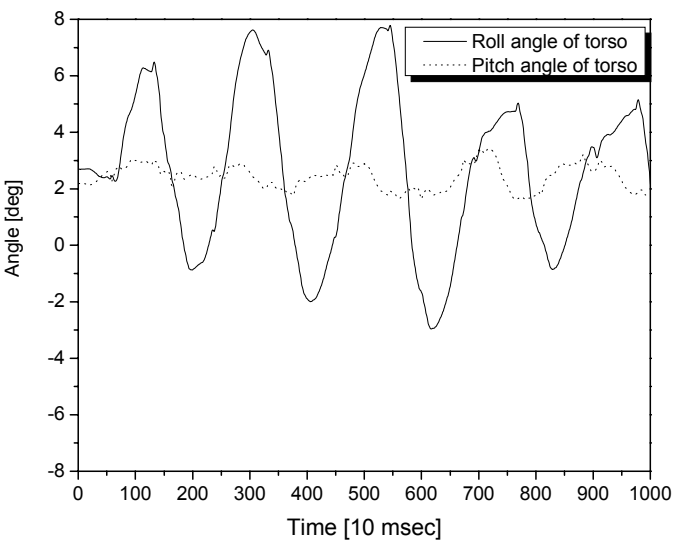

(d) 4 th floor case

(global \& local slopes : +2 deg \& +-2.0 deg in pitch \& roll)

Fig. 23. Experimental results of walking on the spot of various floor cases without consideration of floor conditions 


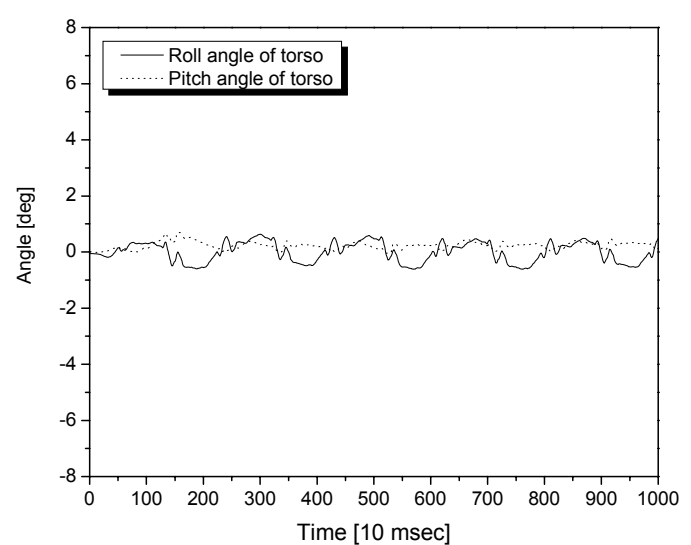

(a) 1 st floor case

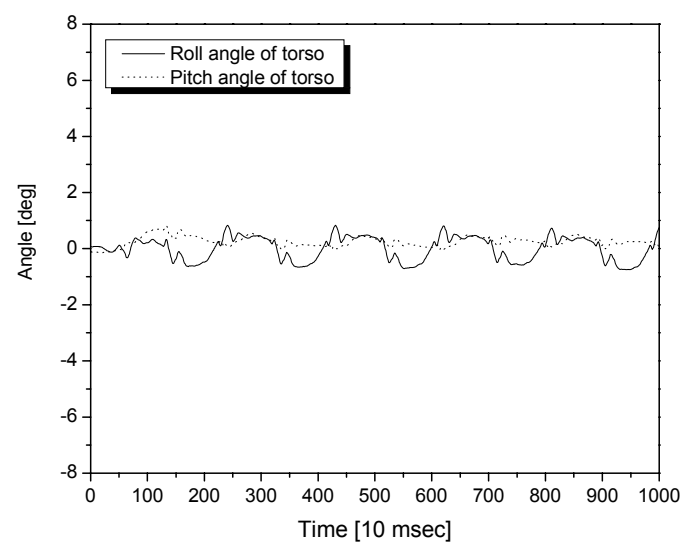

(c) 3rd floor case

(global slope : +3 deg in pitch \& roll)

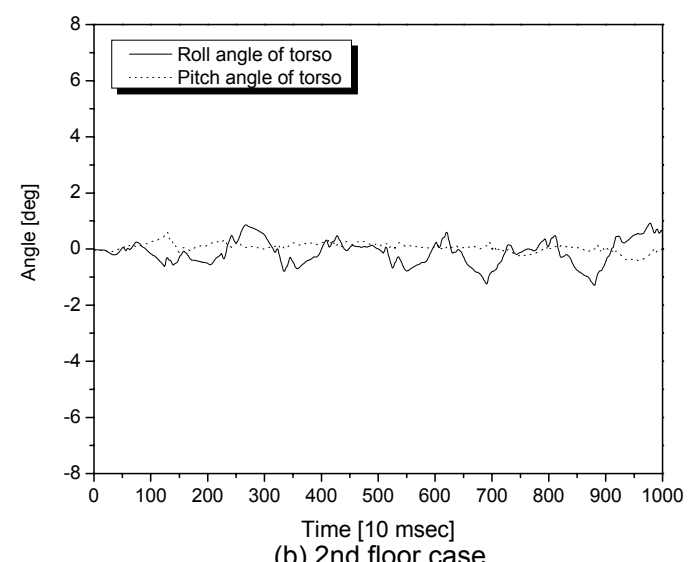

(b) 2nd floor case

(local slope : +-2.0 deg in pitch \& roll)

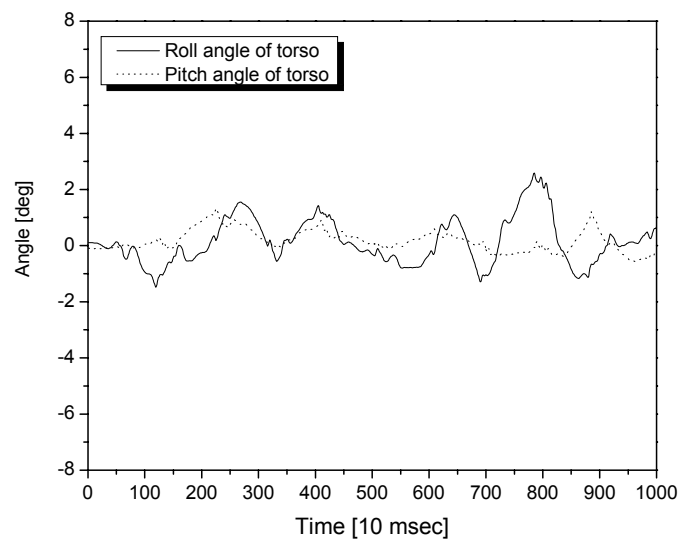

(d) 4 th floor case

(global \& local slopes : +3 deg \& +-2.0 deg in pitch \& roll)

Fig. 24. Experimental results of walking on the spot of various floor cases with consideration of floor conditions 


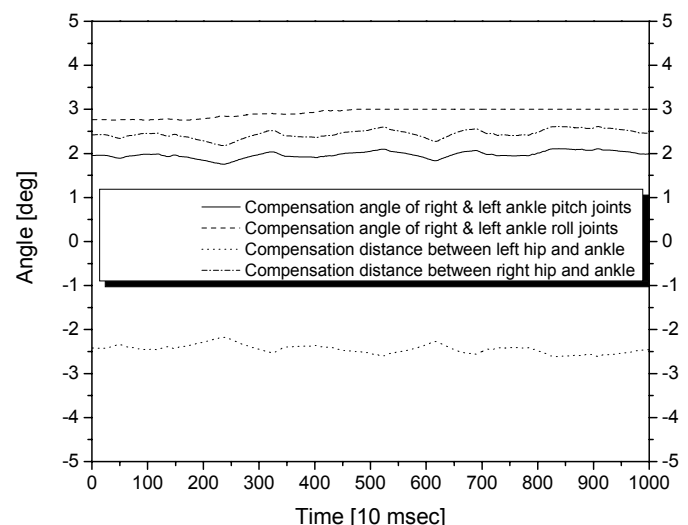

(a) Upright pose control

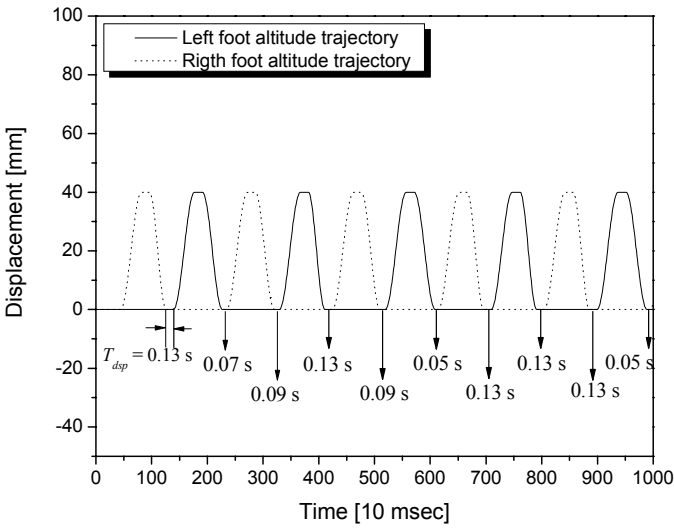

(c) Landing timing control

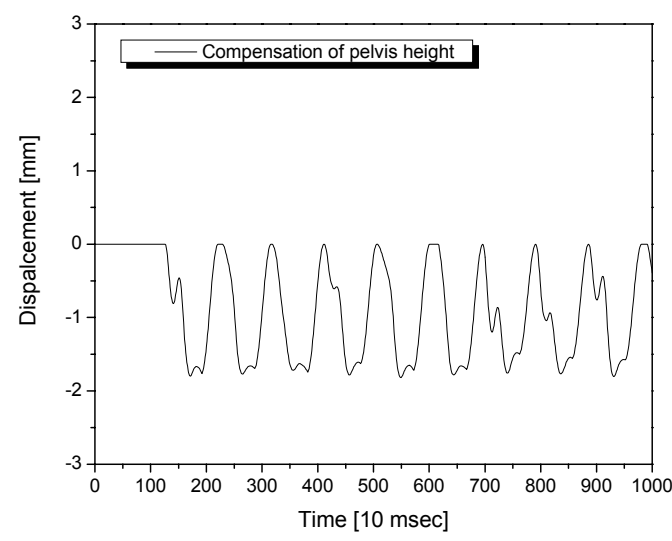

(e) Landing shock absorber

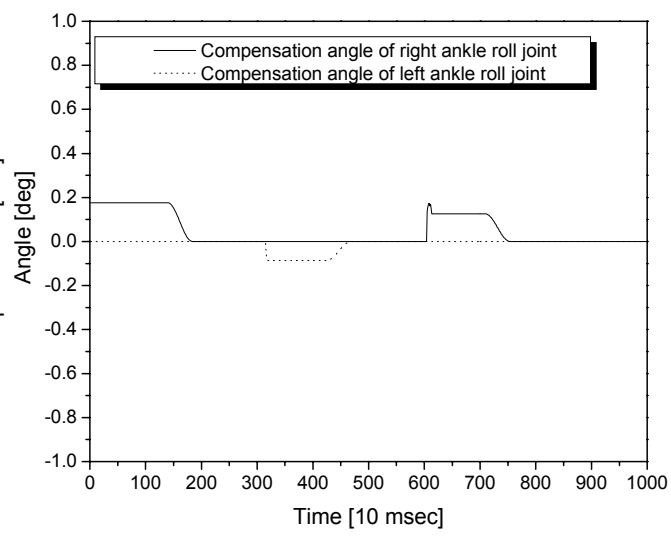

(b) Landing angular momentum control

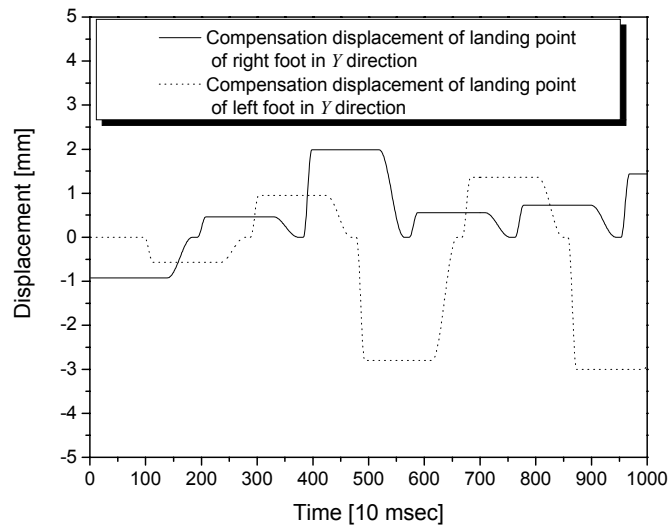

(d) Landing position control

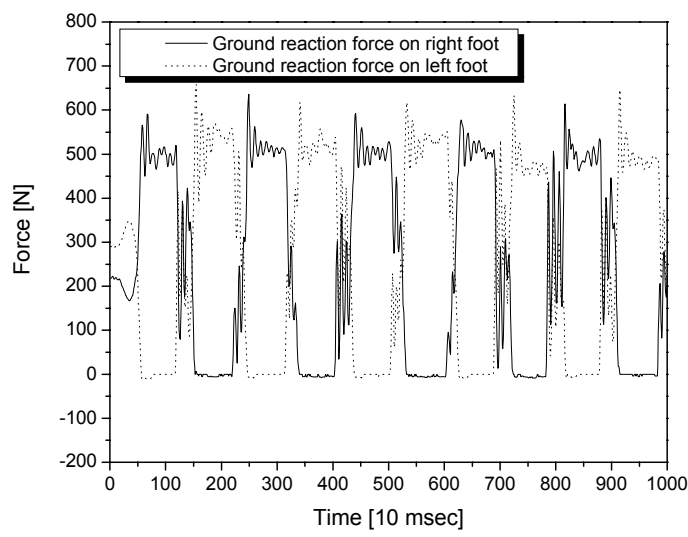

(f) Measured ground reaction force

Fig. 25. Compensatory inputs of online controllers during walking on the spot of 4th floor case 

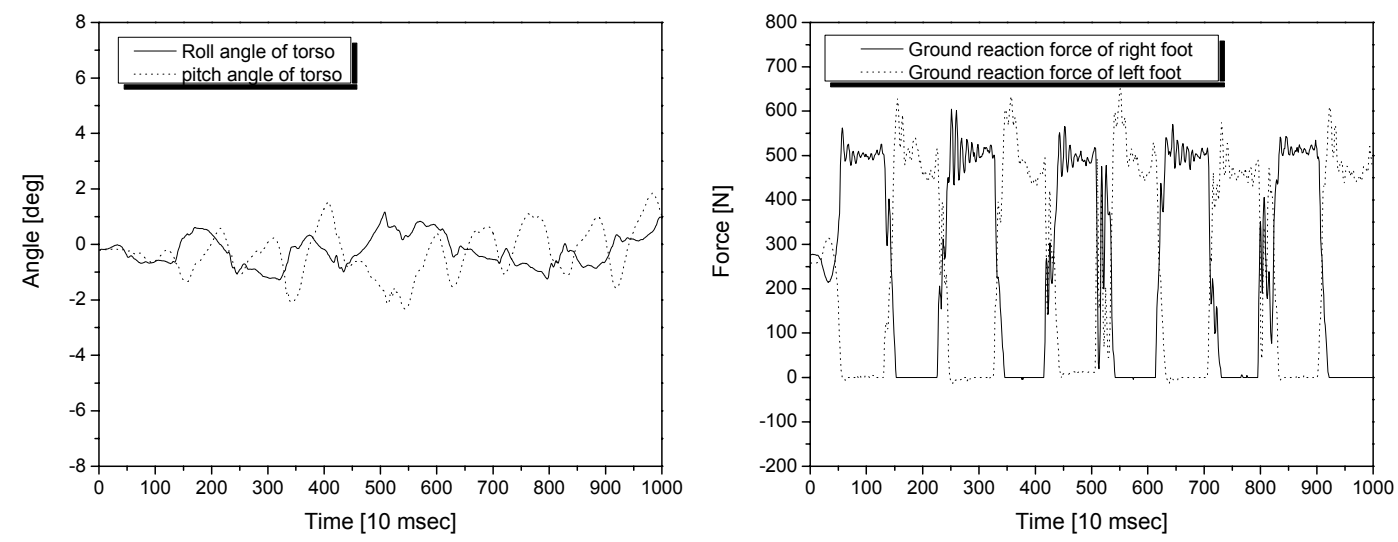

Fig. 26. Experimental results of forward walking on uneven and inclined floor (step length : $200 \mathrm{~mm}$ )

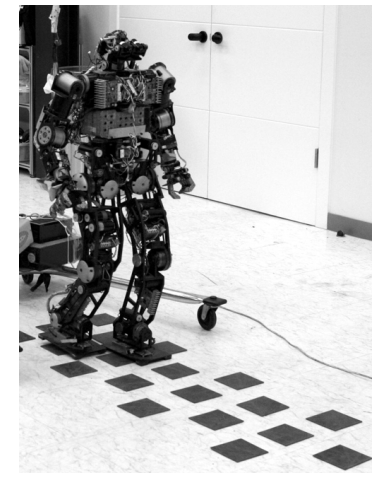

0 second

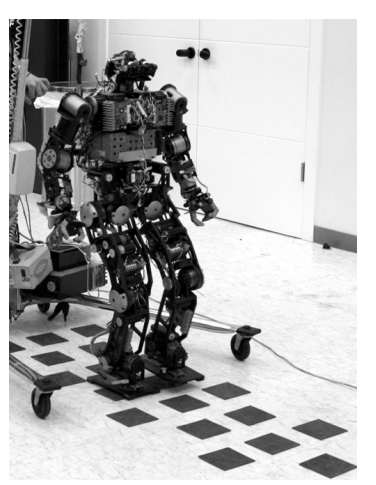

$4 / 3$ second

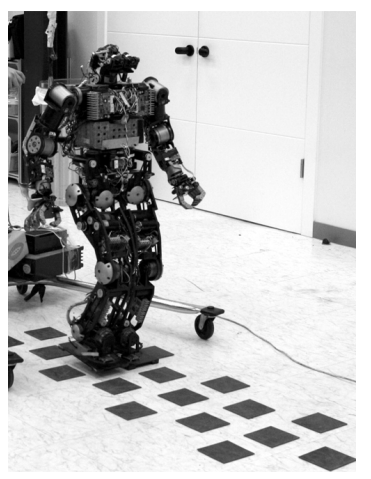

$1 / 3$ second

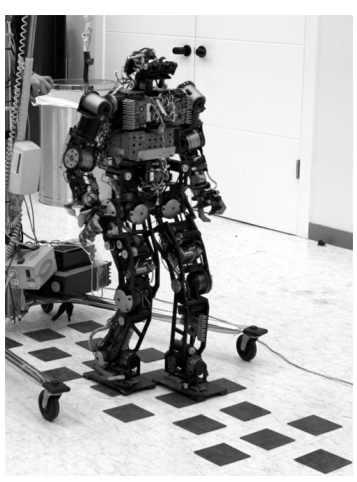

$5 / 3$ second

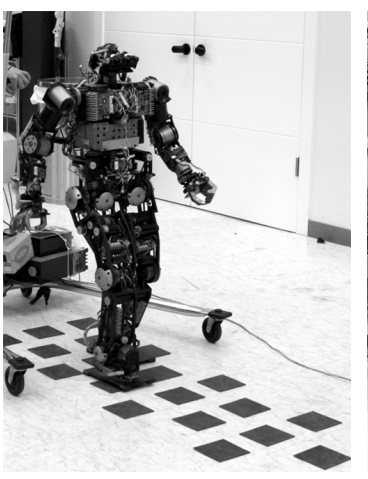

$2 / 3$ second

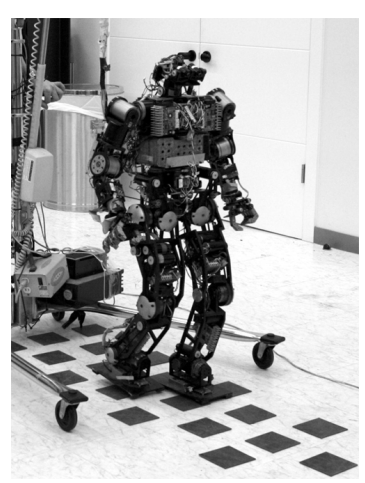

2 seconds

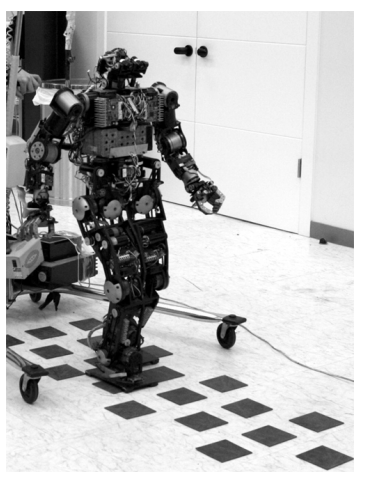

1 second

Fig. 27. Snapshot of forward walking of KHR-2 on uneven room floor (step length : $200 \mathrm{~mm}$ ) 


\section{CONCLUSION AND FUTURE WORK}

This paper described a walking control algorithm for biped humanoid robots that considers an uneven and inclined floor. In the case of the author's previous algorithm, the online controllers were designed without the consideration of the local and global inclinations of the floor. That is, the floor was assumed to be comparatively flat. The previous online controllers worked well for a slightly uneven and inclined floor, but the robot immediately fell down when the floor inclinations exceeded a certain threshold. Hence, six online controllers (Upright pose controller, landing angular momentum controller, landing shock absorber, landing timing controller, landing position controller, and vibration reduction controller) were developed and added to the previous algorithm. These online controllers were designed through simple mathematical models and experiments, and then suitable activation periods were planned in a walking cycle. Each online controller has a clear objective and the controllers are decoupled from each other. To validate the performance of the online controllers, walking experiments on an uneven and inclined aluminum plate were performed. After stable walking on the aluminum plate was confirmed, a forward walking experiment on an uneven room floor was carried out. Successful forward walking was realized, and the effectiveness of the proposed walking algorithm was thereby verified.

As future research, it is necessary to develop a more human-like sole that is ground shape adaptive and ground reaction force absorptive. In the case of a human sole, the thick and soft skin absorbs landing impact and adapts to uneven ground. The authors' biped humanoid robots, KHR-2, HUBO, and Albert HUBO have hard and flat soles with four rubber supporters. If the floor's curvature is large, one rubber supporter among the four rubber supporters may not be in contact with the floor, and consequently the foot landing becomes unstable. In addition, structural vibrations of the sole are generated because it is hard and has little damping property. From this point of view, it is necessary to attach damping systems that have a good force of restitution on the hard aluminum sole.

\section{ACKNOWLEDGEMENTS}

This research was supported by the MOCIE (Ministry of Commerce, Industry and Energy) of South Korea.

\section{REFERENCES}

1. J. Yamaguchi, A. Takanishi, I. Kato.: Development of a biped walking robot compensating for threeaxis moment by trunk motion. Paper presented at the IEEE/RSJ international conference on intelligent 
robots and systems, Yokohama, Japan, 26-30 July 1993

2. K. Nagasaka, H. Inoue, M. Inaba. : Dynamic walking pattern generation for a humanoid robot based on optimal gradient method. Paper presented at the IEEE international conference on systems, man, and cybernetics, 12-15 Oct. 1999

3. Y. Sakagami, R. Watanabe, C. Aoyama, S. Matsunaga, N. Higaki, K. Fujimura.: The intelligent ASIMO: System overview and integration. Paper presented at the IEEE/RSJ international conference on intelligent robots and systems, Lausanne, Switzerland, 30 Sep.- 5 Oct. 2002

4. K. Kaneko, F. Kanehiro, S. Kajita, H. Hirukawa, T. Kawasaki, M. Hirata, K. Akachi, T. Isozumi.: Humanoid robot HRP-2. Paper presented at IEEE international conference on robotics and automation, New Orieans, LA, 26 April - 1 May 2004

5. W. T. Miller III.: Real-time neural network control of a biped walking robot. IEEE Control Systems Magazine. 14(1): 41-48 (1994)

6. C. L. Shih.: Ascending and descending stairs for a biped robot. IEEE Transactions on Systems, Man and Cybernetics. 29(3): 255-268 (1999)

7. J. Yamaguchi, E. Soga, S. Inoue, A. Takanishi.: Development of a bipedal humanoid robot - control method of whole body cooperative dynamic biped walking-. Paper presented at the IEEE international conference on robotics and automation, Detroit, Michigan, 10-15 May 1999

8. K. Hirai, M. Hirose, T. Takenaka.: The development of Honda humanoid robot. Paper presented at the IEEE international conference on robotics and automation, Leuven, Belgium, 16-20 May 1998

9. S. Kajita, F. Kanehiro, K. Kaneko, K. Fujiwara, K. Harada, K. Yokoi, H. Hirukawa.: Biped walking pattern generation by using preview control of Zero-Moment Point. Paper presented at the IEEE international conference on robotics and automation, Taipei, Taiwan, 14-19 Sep. 2003

10. M.Vukobratovic, B. Borovac, D. Surla, D. Stokic.: Biped locomotion. Springer-Verlag (1990)

11. K. Nishiwaki, S. Kagami, Y. Kuniyoshi, M. Inaba, H. Inoue.: Online generation of humanoid walking motion based on fast generation method of motion pattern that follows desired ZMP. Paper presented at the IEEE/RSJ international conference on intelligent robots and systems, Lausanne, Switzerland, 30 Sep. 
12. J. H. Kim, J. H. Oh.: Walking control of the humanoid platform KHR-1 based on torque feedback control. Paper presented at the IEEE international conference on robotics and automation, New Orieans, LA, 26 April - 1 May 2004

13. J. Y. Kim, I. W. Park, J. H. Oh.: Experimental realization of dynamic walking of the biped humanoid robot KHR-2 using zero moment point feedback and inertial measurement. Advanced Robotics. 20(6): 707-736 (2006)

14. Y. Sugahara, T. Hosobata, Y. Mikuriya, H. O. Lim, A. Takanishi.: Realization of stable dynamic walking by a parallel bipedal locomotor on uneven terrain using a virtual compliance control. Paper presented at the IEEE/RSJ international conference on intelligent robots and systems, Las Vegas, Nevada, 27-31 Oct. 2003

15. K. Hashimoto, Y. Sugahara, H. O. Lim, A. Takanishi.: Realization of stable walking on public road with new biped foot system adaptable to uneven terrain. Paper presented at the IEEE/RAS-EMBS international conference on biomedical robotics and biomechatronics, 20-22 Feb. 2006

16. I. W. Park, J. Y. Kim, J. Lee, J. H. Oh.: Mechanical design of humanoid robot platform KHR3(KAIST Humanoid Robot-3:HUBO). Paper presented at the IEEE/RAS international conference on humanoid robots, Tsukuba, Japan, 5-7 Dec. 2005

17. V. T. Inman, H. J. Ralston and F. Todd, Human Walking, London : Williams \& Wilkins, 1981. 